\title{
EXCHANGEABLE END EFFECTORS FOR THE ARMY \\ EXPLOSIVE ORDNANCE DISPOSAL (EOD) ROBOT
}

by

Deborah M. Chubb

Thesis submitted to the Faculty of the

Virginia Polytechnic Institute and State University

in partial fulfillment of the requirements of the degree of

MASTER OF SCIENCE

in

Industrial and Systems Engineering

APPROVED:

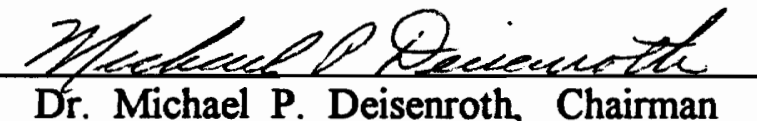

Dr. Michael P. Deisenroth, Chairman

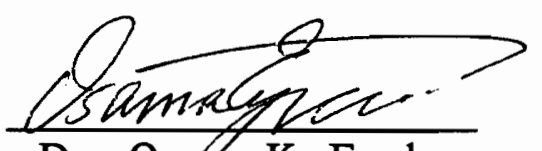

Dr. Osana K. Eyada

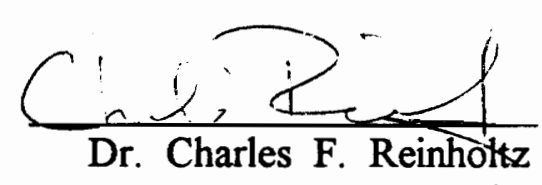

,

May 1993

Blacksburg, Virginia 
LD

c.2

565

1993

C529

$+2$ 


\title{
EXCHANGEABLE END EFFECTORS FOR THE ARMY \\ EXPLOSIVE ORDNANCE DISPOSAL (EOD) ROBOT
}

\author{
by \\ Deborah M. Chubb \\ Committee Chairman: Michael P. Deisenroth \\ Industrial and Systems Engineering
}

(ABSTRACT)

Explosive Ordnance Disposal (EOD) is assigned the mission to render safe and/or dispose of any device, conventional, nuclear, biological, chemical, or improvised, that may cause injury to personnel or damage to property. Teleoperated mobile robots have been fielded to make the job of the EOD soldier less hazardous. The current model in use is the Security Explosive Ordnance Disposal (SEOD) robot. The future model is the RCT Rover. These robots are designed to specifically target improvised explosive devices (IEDs) -- homemade bombs. With their present design these robots have limited capabilities. Only one gripper, which is bolted onto the end of the arm, is provided.

It was the objective of the research to take the first step toward increasing the flexibility of this robot by applying technology which presently exists in the industrial robotics area. A feasibility study was proposed which considered both hardware and control issues of proposed changes. A quick exchange device was proposed as well as numerous end effectors to make the robot more adaptable to any given situation. Control and feedback system issues was also investigated that allowed the telerobot to have autonomous control during the end effector interchange sequence. 


\section{ACKNOWLEDGEMENT}

I wish to thank Dr. Michael Deisenroth for his guidance and support. He always managed to find time in his busy schedule to work with me and keep me focused. I would also like to thank Dr. Charles Reinholtz for sharing his experience, ideas and advice, and Dr. Osama Eyada for his time. Equally responsible for my success are some of my fellow graduate students who were willing to take time to explain to me prerequisite course work and computer programs that I did not have experience in. Special thanks go to Carol Vaughan, Mark Pifer, Janis Terpenny, and Andy Hansbrough. Finally, I would like to thank CPT Terra Lee for taking the time to help me track down information from government agencies, and for offering sage advice, guidance and support throughout this endeavor. 


\section{TABLE OF CONTENTS}

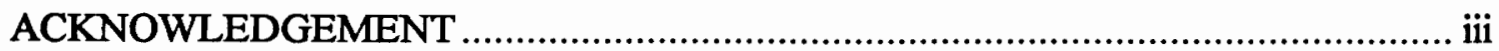

LIST OF FIGURES AND TABLES .................................................................... iv

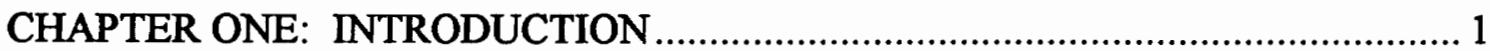

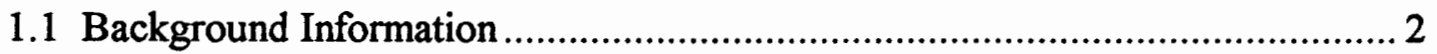

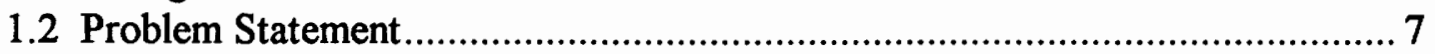

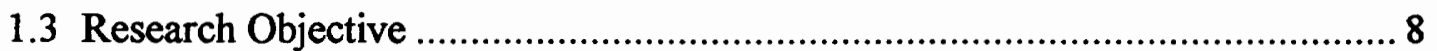

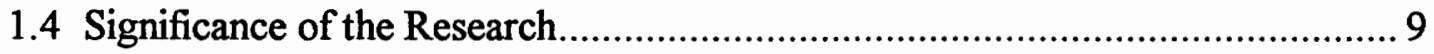

CHAPTER TWO: LITERATURE REVIEW...................................................... 10

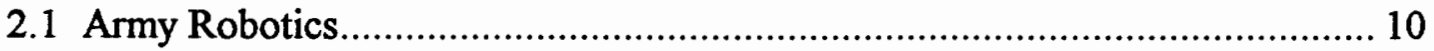

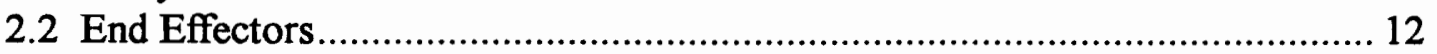

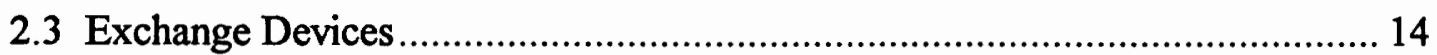

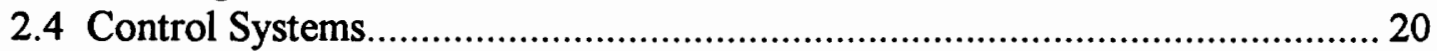

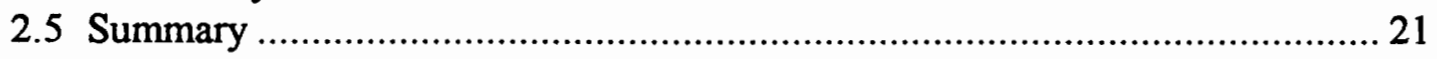

CHAPTER THREE: ROBOT COMPONENT ANALYSIS ......................................23

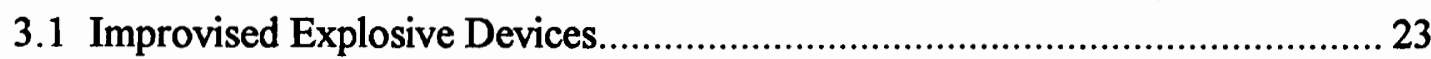

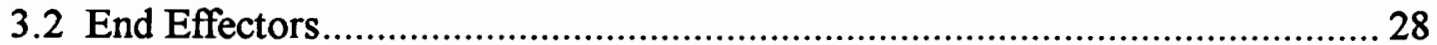

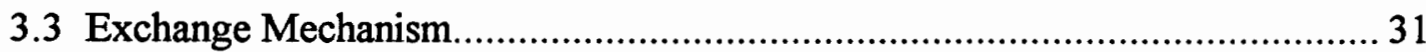

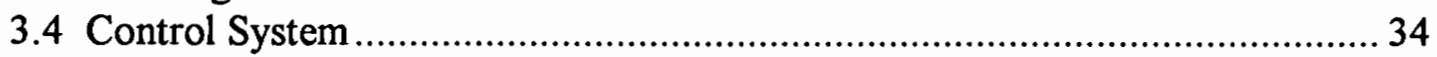

CHAPTER FOUR: ROBOT SYSTEM INTEGRATION.........................................

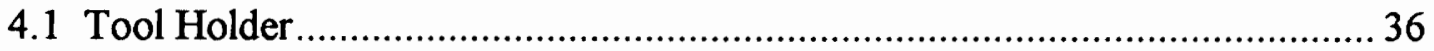

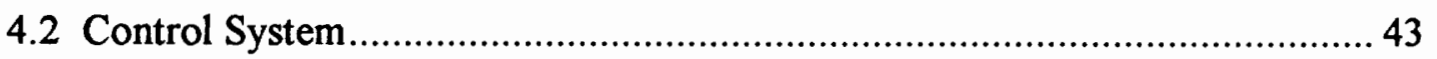

CHAPTER FIVE: SUMMARY AND RECOMMENDATION FOR FUTURE STUDY

APPENDIX

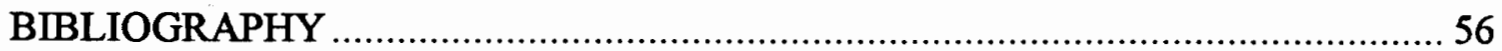

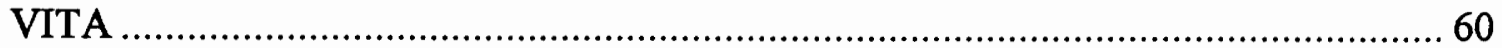




\section{LIST OF FIGURES AND TABLES}

\section{FIGURES}

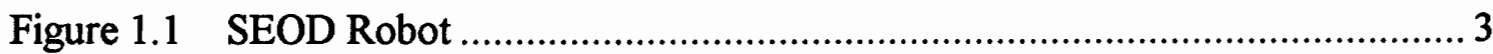

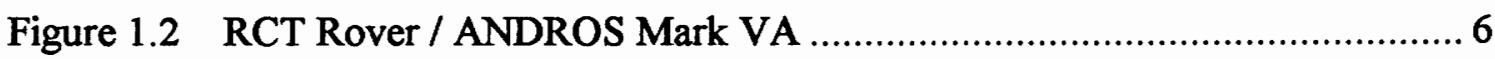

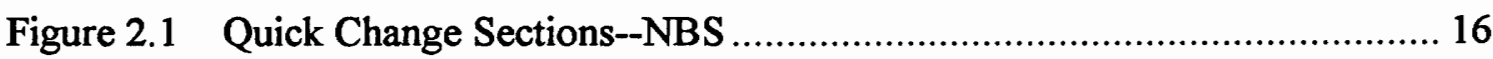

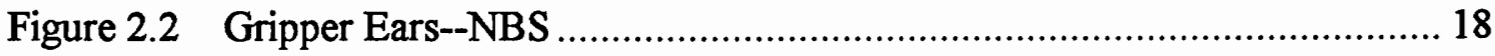

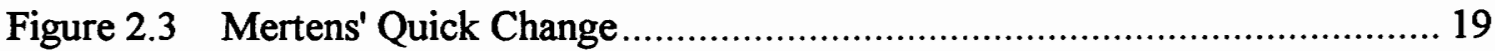

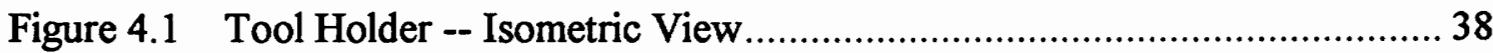

Figure 4.2 Tool Holder -- Mechanical Drawings ..................................................... 40

Figure 4.3 Gripper Adapter With Ears ............................................................... 41

Figure 4.4 Tool Holder With Gripper Adapters .................................................. 42

Figure 4.5 RCT Rover Functional Block Diagram.............................................. 44

Figure 4.6 Autonomous Control Wiring Change …............................................... 45

\section{TABLES}

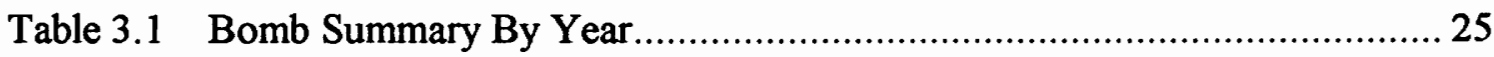

Table 3.2 Improvised Explosive Devices............................................................ 26

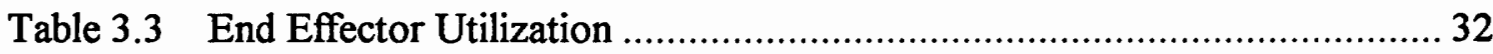




\section{CHAPTER ONE}

\section{INTRODUCTION}

The United States Army Explosive Ordnance Disposal (EOD) robotic program is founded on the Royal Army Ordnance Corps' (RAOC) doctrine. The RAOC has extensive experience using a robotic device in Northern Ireland and offers an excellent improvised explosive devices (IED) course which some U.S. soldiers are fortunate to attend. Unfortunately, the British doctrine is limited to an urban environment which is not practical on a battlefield. [7]

The Department of Defense has assigned the Secretary of the Navy as the single service manager for EOD Training and Technology (EODT\&T). This includes the research and development (R\&D) of EOD tools and equipment. Each military service is authorized to conduct EOD R\&D programs that satisfy service unique requirements but they must be coordinated with the EOD Program Board to avoid duplication. In order to benefit from the RAOC's training program and extend its practicality to the global mission requirements of the United States, the Army has established the EOD Robotic Master Plan. The proposed developmental strategy takes advantage of technological advances in stages. The first stage has already been implemented with the fielding of the Security Explosive Ordnance Disposal (SEOD) robot. The design of the SEOD robot has limited capabilities and is primarily restricted to targeting IEDs. Stage two of the master plan incorporates the technology to use specialized sensors for reconnaissance and chemical/radiological detection. The RECORM (Remote Controlled Reconnaissance Monitor) is a small lightweight, under 100 pounds, teleoperated device designed for route 
reconnaissance and the monitoring of unexploded ordnance and IEDs of all types. It will have the capability of video taping the reconnaissance and render safe procedures. Actual fielding of this system is not expected until first quarter fiscal year 96. Stage three replaces the SEOD robot with the Navy developed Remote Control EOD Tool and Equipment Transporter (RCT Rover), commercially known as the ANDROS Mark V-A. Both Navy and Air Force EOD units currently have this robot. The Army plans to field this system gradually over two or three years due to funding constraints. The first system should be fielded in fiscal year 95. The fourth and final stage replaces the RCT Rover with a new robotic device called the Remote Ordnance Neutralization System (RONS). The RONS will give the "EOD soldier the increased capability of performing render safe procedures (RSPs) remotely and by teleoperation." [6] It will be the first system with battlefield specifications. The RONS will be in the 900 to 1,500 pound weight class and be powered by diesel fuel. Control will still be by radio frequency or fiber optics. Operations will be performed robotically and by teleoperation. The projected fielding date is fiscal year 2000 .

\subsection{BACKGROUND INFORMATION}

The Security Explosive Ordnance Disposal (SEOD) robot is a teleoperated mobile system which is designed to "provide all the capabilities required for inspection, removal and/or rendering safe of hazardous devices from safe distances." [21] It is manufactured by Standard Manufacturing Company. The SEOD robot is illustrated in Figure 1.1. The SEOD robot has limited capabilities in that it is inflexible to changing situational demands. This inadequacy is concentrated in two areas. The first is that the SEOD robot comes 


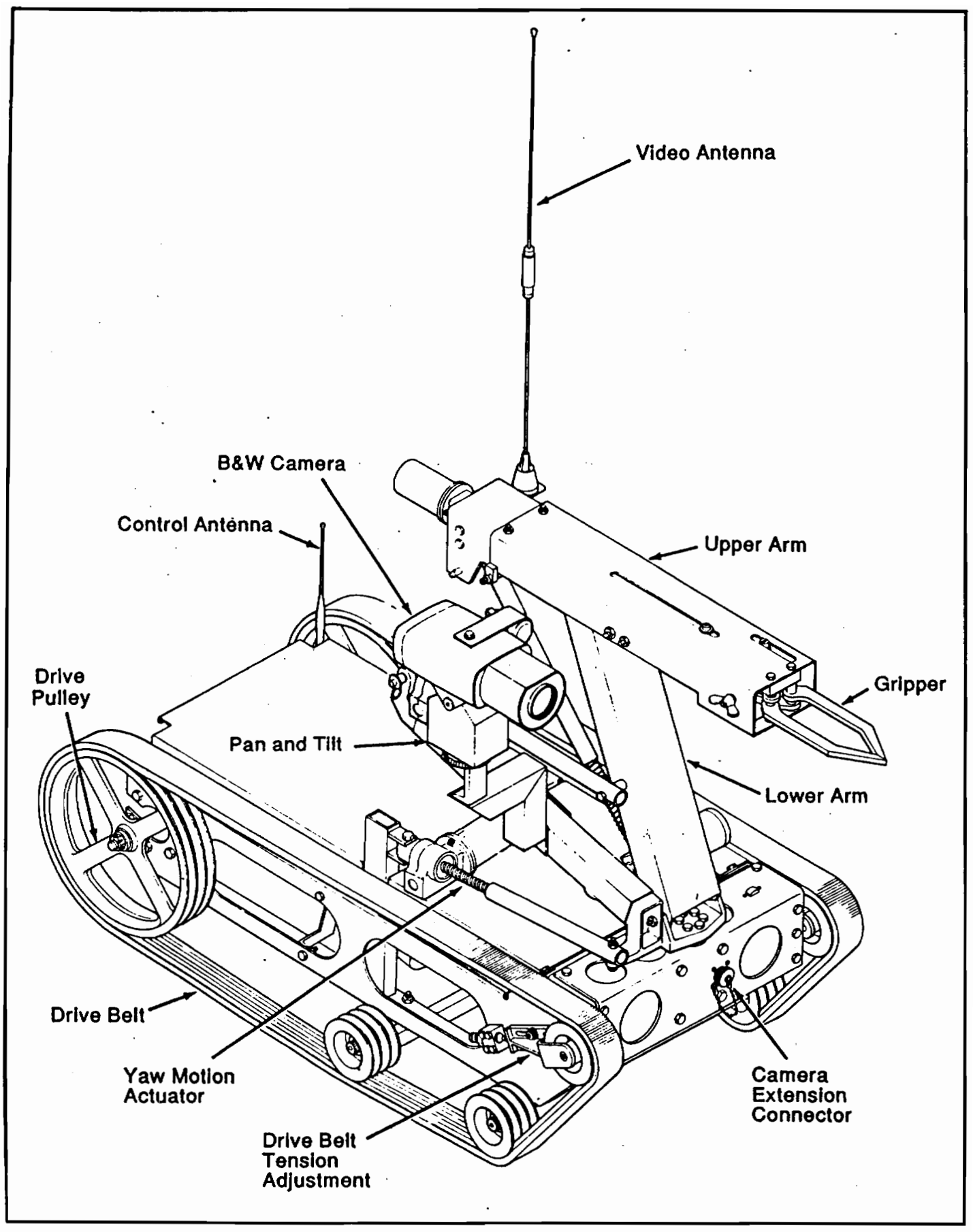

Figure 1.1 SEOD Robot 
equipped with only one gripper. This severely restricts the operational effectiveness of the robot. A selection of end effectors would make the robot more adaptable. It should be noted that additional attachments are also provided which can be bolted to the upper robot arm. They include a shotgun, water disrupter, microphone, and x-ray equipment. These attachments should not be confused with the end effector since they are mounted directly to the robot arm (not the wrist), and provide a specific function. The second drawback is that valuable time is lost in preparing the robot. Despite witnesses, the situation downrange is never completely certain. The EOD technicians have to "bestguess" the situation and make whatever attachments they deem suitable prior to sending the robot downrange. If the choice of attachment(s) is wrong or if the situation requires that more than one task be performed, then the robot has to be brought back uprange to have the changes made. These circumstances could be repeated several times. This cost of time is compounded when working in a contaminated environment when two soldiers have to be exposed to possible high levels of radiation, or chemical or biological contaminants. These limitations make the SEOD robot more of a burden then a useful tool. At this point in time it is still easier for the EOD technician to approach the suspect IED in person rather than use the robot.

The next generation of explosive ordnance disposal robot is the RCT Rover. This system will begin replacing the Army SEOD robot in 1995 . It is already being fielded to Navy and Air Force EOD units. The RCT Rover is also a teleoperated mobile system designed to target improvised explosive devices in an urban environment. It is commercially known as the ANDROS Mark V-A and is manufactured by Remotec in Oak Ridge, Tennessee. It has articulated tracks which enable it to cross rough terrain and 
obstacles, climb stairs, and cross ditches as wide as 24 inches. The Rover is 28 inches wide, 41.5 inches high, and 31 inches long (62 inches long with the tracks horizontal). Depending on the amount of optional equipment included, it can weigh from 550 to 700 pounds. The manipulator system has a 210 degree shoulder pivot, a 210 degree elbow pivot, and continuous gripper rotate. Wrist pivot and shoulder rotate are options that are available. It has a fixed 2-finger angular gripper. The Rover can reach 66 inches horizontal and 104 inches above the floor. It's lift capacity is 35 pounds at 66 inches and 100 pounds at 16 inches reach. The robot comes equipped with two low-light CCD cameras. A black and white camera is mounted on the arm above the gripper and a color surveillance camera (with pan and tilt) is mounted on the body. A variable-intensity, quartz-halogen light is attached to each camera. A microphone and speaker are also mounted on the vehicle. Power is supplied by two 12 volt batteries on the vehicle and one on the control console. Speed is variable, from 1 to 16 inches per second. The control console is mounted on a two-wheeled dolly and includes a color TV monitor, speaker, and microphone.

While the RCT Rover is much more rugged than the SEOD robot, it still has the same limitation of having only one two-finger gripper on board. Remotec does offer a heavy-duty gripper and double pincer end effectors but they function the same (twofingers with an angular closing) and must be physically mounted. Operational time can be reduced and flexibility added by incorporating quick change technology and mounting a selection of end effectors on board. The RCT Rover (ANDROS Mark V-A) is shown in Figure 1.2. 


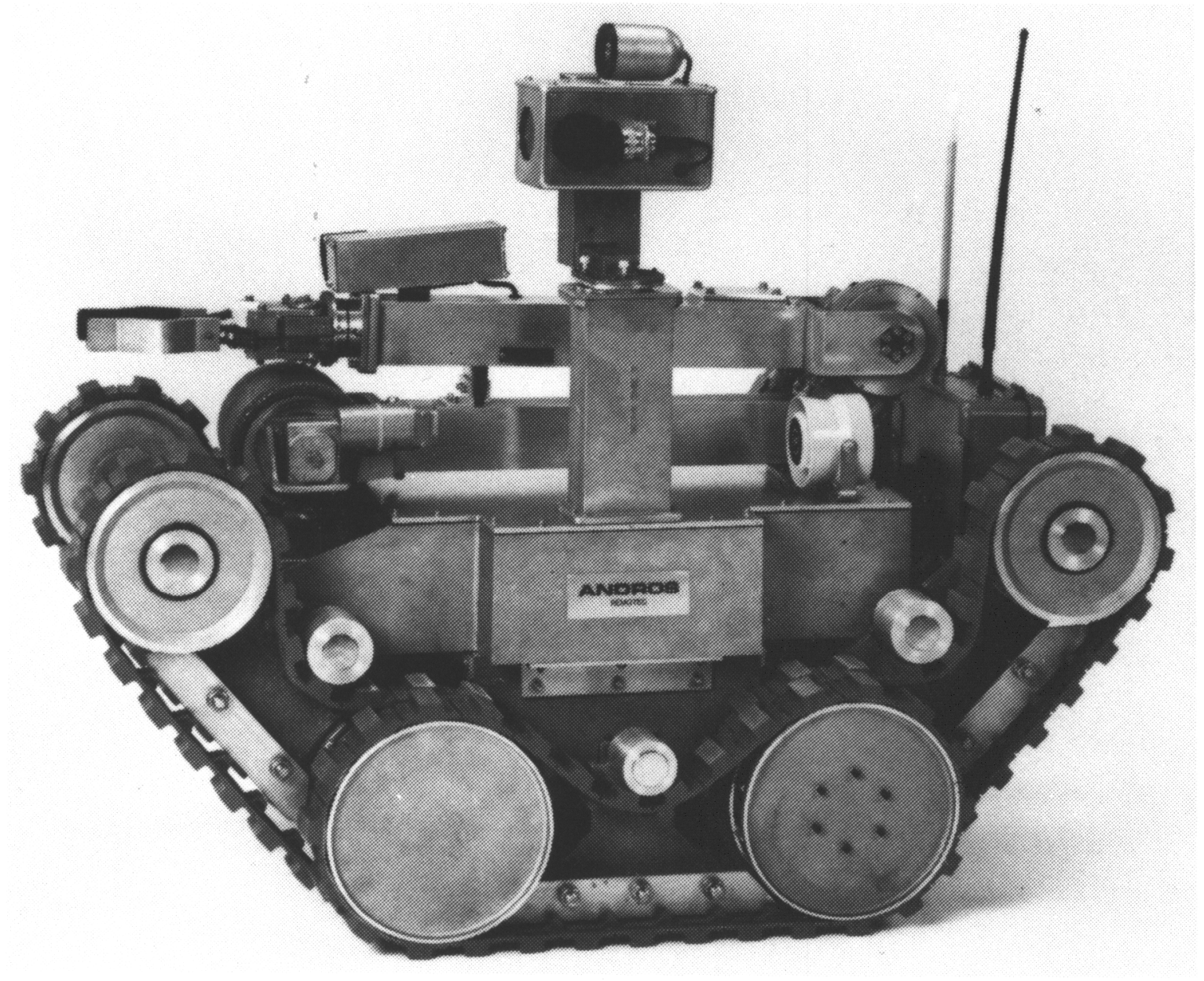

Figure 1.2 RCT Rover / ANDROS Mark V-A 


\subsection{PROBLEM STATEMENT}

The SEOD robot comes equipped with just one gripper. It has two curved fingers which operate like scissors with a center pivot point. The RCT Rover also comes equipped with one gripper but optional gripper designs are available. These grippers are all in the angular closing, two-finger family but the size and design of the fingers vary. Since this robot was built for the nuclear industry, the grippers are large and heavy duty and designed to perform rigorous duties. These duties range from using tools to vacuum contaminated water or taking a radiation survey to turning valves on and off.

Using robots in the EOD field requires a manipulator system with dexterity and flexibility. With the combination of a poorly designed and weak manipulator system and a simplistic gripper, the SEOD robot is unable to do its job as it was intended. The RCT Rover has a good manipulator system with its continuous wrist rotation and robust design but any gripper which can be chosen for use is large and cumbersome. Operations against improvised explosive devices require end effectors which are capable of lifting moderate loads but which can also function in and under confined spaces in a dexterous manner. The end effectors also need to be capable of handling the majority of package configurations.

A redesign of EOD robotic vehicle system tooling is needed. A complete redesign of the robot may not be warranted. A study is needed which will consider adapting the current design by applying technology which currently exists in the industrial robotics arena. A feasibility study which considers both hardware and control issues of these changes is proposed. This research addresses the application of exchangeable end 
effectors, the required exchange mechanism to provide the necessary mechanical and electrical interfaces between the robot and the tooling, and the control/feedback method for the system.

\subsection{RESEARCH OBJECTIVE}

While there are problems with the tooling design, these shortcomings can be addressed by applying current technology. There are manipulators used in industry today which are small, lightweight, and intelligent but with the strength to handle moderate loads. They are used in a variety of applications from picking up silicon wafers and placing computer chips to reorienting a part for machining. Regardless of whether or not the application requires a state-of-the-art end effector or only a stock gripper, the end effector is the key component in developing a smooth and efficient operation.

In order to fully accomplish the redesign of the SEOD robot or RCT Rover, a three phase approach is needed. The first phase is the feasibility study. This study is the objective of this research and will be discussed in the next paragraph. The experimental phase is the second phase and will involve obtaining the SEOD robot or RCT Rover for laboratory work and testing. Once the robot is redesigned and functioning, the third phase will be initiated. This phase is the implementation phase and will involve deploying the improved SEOD robot or RCT Rover to test units in the field for functional testing and evaluation under actual conditions. If the robot performs as it is intended, it will be fielded to the remaining EOD units. 
This proposed research is limited to the feasibility study introduced above. The objective of this study is to show the viability of using existing industrial automation technology on Army EOD robotic vehicles. Specifically, the study considers the redesign of the tooling on the SEOD and RCT Rover robots. The RCT Rover is used as the reference for the actual hardware redesign. The redesign incorporates a quick change mechanism and several exchangeable end effectors. In conjunction with the redesign, a control/feedback system is proposed that will allow for autonomous control during the end effector exchange sequence and teleoperator control for all other operations. The selection of end effectors is based on the experience of the researcher within the EOD field regarding the types of IEDs found and in what scenarios. An overlap of end effector usage is desired.

\subsection{SIGNIFICANCE OF THE RESEARCH}

The EOD field has great potential for the application of robotics. EOD technicians are "highly skilled personnel who are at considerable risk during performance of render safe procedures on explosive devices." [16] Although the Security Explosive Ordnance Disposal (SEOD) robot and the RCT Rover were used as the platform for this research, the results can be incorporated in future models. The ability of any EOD robot to use a multitude of different end effectors increases both its flexibility and efficiency. 


\section{CHAPTER TWO \\ LITERATURE REVIEW}

This literature review provides a summary of articles covering the topics of Army robotics, end effectors, exchange devices, and control systems.

\subsection{ARMY ROBOTICS}

Herman [8] outlines the joint service materiel acquisition process. He points out that as established by the Department of Defense (DOD) Directive 5160.62, the Navy is the single service manager for EOD Training and Technology. While each service is authorized to conduct their own research and development (R\&D) programs, all EOD programs must first be approved by the EOD Program Board to avoid duplication of efforts. This directive also established the research and development funding line.

The Army interfaces with the joint service EOD materiel acquisition process in three phases. The combat developer initiates the first phase by drafting the materiel requirements document. He must then obtain the final approval and award of a catalog of approved requirements documents (CARDS) number by Headquarters, Training and Doctrine Command (HQ TRADOC). Once the EOD Program Board staffs the approved requirements document, phase two begins. This phase consists of sending the requirements document to the Navy Explosive Ordnance Disposal Technology Center (NAVEODTECHCEN) at Indian Head, Maryland to begin the R\&D process. Phase three 
commences with the implementation of the full scale R\&D program by the NAVEODTECHCEN once funding is authorized.

The Army currently has four major R\&D materiel development programs under development with the Navy. They are the remote controlled reconnaissance monitor (RECORM), the remote ordnance neutralization system (RONS), the mobile ordnance disrupter system (MODS), and the rifle disrupter of unexploded ordnance (RIDX). Twelve other programs have been initiated and will transition into a full scale R\&D program if proved technically feasible.

SMC 101-588 [21] is the operating manual for the Security Explosive Ordnance Disposal (SEOD) robot. It provides general information on the major components, the leading particulars, operating and maintenance instructions, special tools and test equipment, and guidelines for use and shipment. The SEOD robot weighs 196 pounds, is 48 inches long and 23 inches wide. It utilizes a rubber belt track drive system. The primary control mode is by radio with a range of 900 feet. The secondary control mode is by hard wire through a 325 foot fiber optic cable. Power is generated by two twelve volt batteries mounted on the robot. The robot manipulator has a lift capacity of 20 pounds at its maximum reach and a crush capacity of 30 pounds. The arm can reach 54 inches above the floor and extend 28 inches to the front. The combination of gripper and arm give the operator five degrees of freedom.

Malone, et al. [15] reviews robotic/telerobotic issues in the U.S. Army. The areas of focus are remote vehicle driving and explosive ordnance disposal. These areas were chosen based on their suitability for robotic application. Three control modes are 
discussed -- autonomous, telerobotic, and supervisory. The supervisory control mode is the middle ground between the constant human interface of telerobotic control and the complete machine independence of autonomous control. The authors state that manual control of a manipulator in a teleoperation control system is highly demanding of operator skills. The following control schemes have been developed for telerobotic control: individual joint control, (2) resolved motion control, (3) replica or master-slave control, and (4) force control.

\subsection{END EFFECTORS}

Alvite [1] lists the four most common types of end effectors -- pneumatic, vacuum, electric, and hydraulic. He states that the pneumatic end effector is the most widely used due to its ease of use, installation, service, versatility, high payload, and reliability. Alvite believes that there are three considerations to take into account when choosing an end effector: (1) the type of application plus the work environment should be examined, (2) the weight of the part -- in order to remain within the load capacity of the robot the combined weight of the part and end effector must be figured, and (3) geometry of the part --the item must be handled firmly and securely. Failure to do so could cause damage to the end effector, creating a safety hazard.

Hessler [12] examines the factors to consider when choosing commercially available end-of-arm tooling. He starts by listing the general factors to consider. The most important consideration is the weight of the end effector followed by its physical size, the type of feedback required, the working media available, and the amount of force which is 
required. Components which have applications with end effectors are linear actuators which can provide an additional axis of movement or extension, and rotary actuators which when used in a wrist can add additional axes of rotation. End effectors may be vacuum cups which are lightweight and flexible, magnetic, or grippers. There is a wide range of styles and sizes of grippers. Hessler states that it is necessary to look at the parameters that effect the gripper. The working media available will guide the selection. Air is easy to work with, clean, and readily available. Hydraulic grippers have more grip force and can handle heavier loads. Electric grippers offer better control but have the least amount of force. Whether or not feedback is required and the type of feedback is another consideration when looking for standard grippers. The type of jaw motion depends on the application. Parallel jaws maintain a constant gripping area and force regardless of the size of the object although the bounds of the jaw opening are limited. An angular motion has a greater jaw opening area which gives the gripper a wider range of applications. The object's surface, shape, size, and weight will determine how fast it can be moved and how it should be grasped. Many grippers provide the option of gripping internally or externally. The last parameter to consider is safety. Hessler recommends a four to one ratio of grip force to part weight for objects being gripped without formed tooling. The author summarizes that it is not always necessary to design a special end effector. By using commercially available end of arm tooling, time and money can be saved in design, installation, and maintenance.

Many companies are in the end effector market. Some just design grippers and tooling for specific types of industries, i.e. steel and automotive, while others offer standard stock grippers with modifiable fingers. Standard parallel and angular grippers are sold by Robo Hand Inc., PHD Inc., and Products For Automation (PFA). PFA also offers 
vacuum grippers. Zaytran Inc. sells only parallel grippers while Mack Corporation sells only angular grippers. Catalogs can be obtained by calling any of these companies.

\subsection{EXCHANGE DEVICES}

An exchange device is used when a single robot needs to perform different tasks using different tools. It provides the mechanical and electrical interfaces between the robot and the tools. The device consists of two pieces, the robot adapter and the tool adapter. The robot adapter attaches to the wrist of the robot and each tool will have the corresponding tool adapter affixed. With the exchange device, a robot can quickly and automatically change tooling without manual assistance.

Wright [23] describes an exchange system developed at Intelledex for a light assembly robot. The design objectives for the exchange mechanism were: (1) light weight, (2) axial accuracy, (3) longitudinal accuracy, (4) rotational accuracy, (5) coupling stiffness, (6) torque capacity, (7) connection of two pneumatic lines, (8) full rotational capability of the pneumatic lines, (9) connection of twelve electrical lines, (10) full rotation capability of the electrical lines, and (11) adaptability to a variety of configurations. Axial, longitudinal, and rotational accuracy gives the robot the repeatability to use previously loaded programs to change tooling without having to reorient itself first. The language Intelledex used to operate the robotic arm was 'Microsoft Basic'.

Crawford, et al. [4] describes a computer-controlled, interchangeable end effector system. Two quick change adapters were designed to fit large and small end effectors. 
The large adapter weighs approximately twelve pounds and has a load capacity of 150 pounds. It provides six pneumatic ports and thirty-two electrical connections. The small adapter weighs only two pounds and has a load capacity of twenty-five pounds. It comes with four pneumatic ports and twenty-four electrical connections. The system is designed with intelligent end effectors in mind. A pre-processor is provided to furnish closed loop control of the end effector and real time feedback to the operator. Discrete $\mathrm{I} / \mathrm{O}$ allows the pre-processor to communicate with most robot controllers. This also allows the end effector system to interface with many types of robots. The sub-programs are written in either $\mathrm{C}$ or assembler.

Vranish [22] reports on a quick change system developed by the National Bureau of Standards for its Automated Manufacturing Research Facility. The quick change device was designed to meet the following specifications: (1) a maximum payload of fifty pounds at twenty inches from the robot wrist must cause no more than a 0.14 degree angular tilt to the robot wrist $Z$ axis, (2) a torque of 500 in-lbs about the robot wrist $Z$ axis must cause no more than a 0.14 degree roll between the two sections, (3) three $1 / 4$ inch diameter pneumatic lines and six $1 / 4$ inch diameter dual purpose hydraulic or pneumatic lines, (4) thirty-eight electrical connections capable of frequency ranges from DC to 2 $\mathrm{MHz}$, (5) fail safe design for the locking mechanism, (6) repeatability of mating, and (7) the physical dimensions must not exceed a weight of twenty pounds, an axial length of seven inches, and a 7 1/4 inch diameter. The quick change consists of two sections. One plate mounts on the robot wrist and contains the locking mechanism. It also acts as a manifold for the hydraulic fluid and air. The second plate attaches to the end effector. This plate holds the taper for the locking mechanism. The electrical connections and fluid channels are positioned in a circular pattern about the locking mechanism (Figure 2.1). 


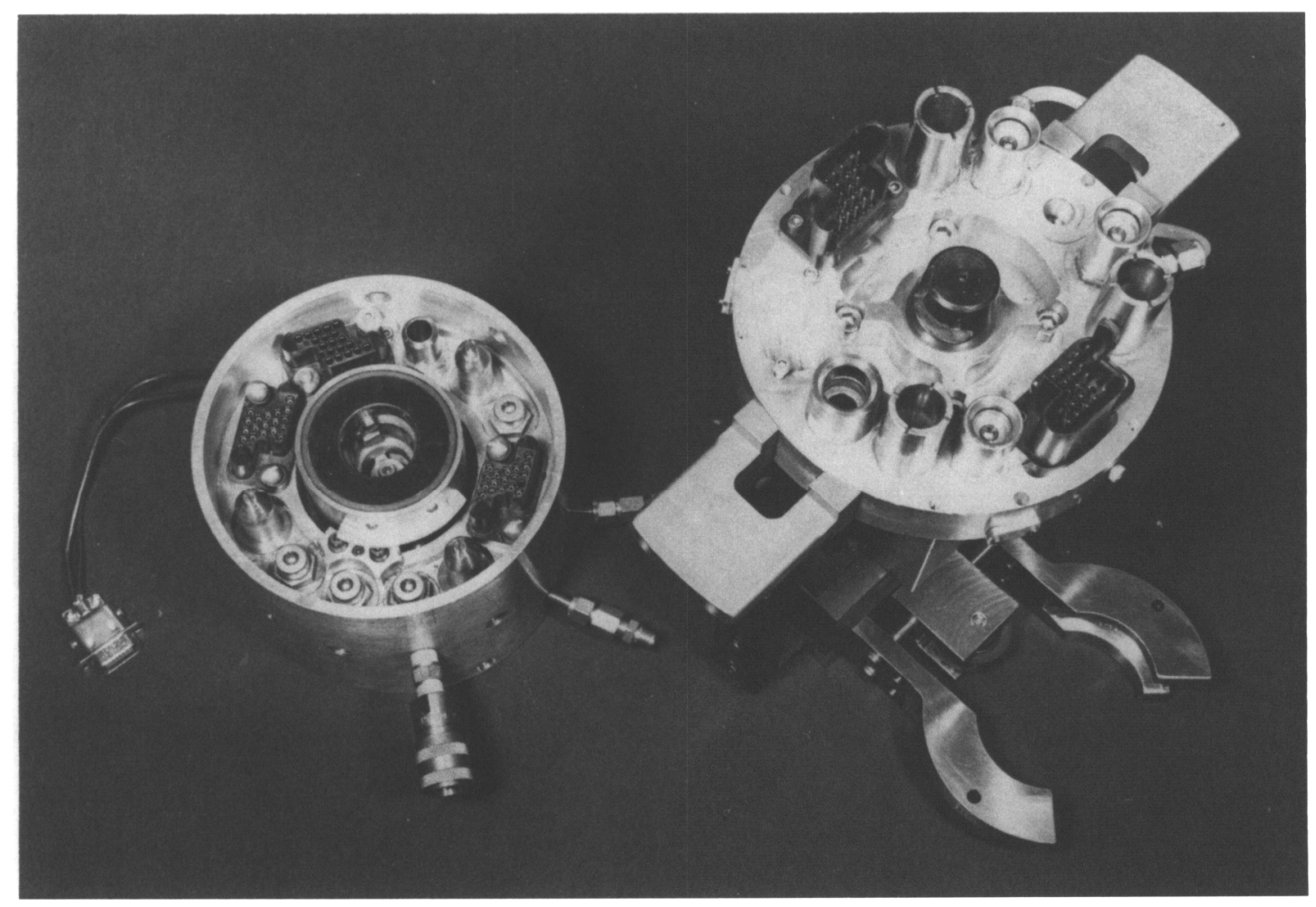

Figure 2.1 Quick Change Sections--NBS 
In addition to the quick change system, a holster was designed. The holster has to hold and position the end effectors accurately so that the robot can make repeated tool changes. Vibration isolators were built in for compliance since a robot has very little compliance when its wrist is held close into the waist. By angling the holster 15 degrees and adding ears onto the second plate, the robot can correct minor misalignment with ease (Figure 2.2).

Mertens [17] developed a quick change mechanism for use by industrial robots in palletizing applications. The exchange mechanism was required to have a load capacity of 22 pounds, have at least six pneumatic channels at 100 PSI and 24 electrical connections, and have full rotational capability. Mertens' adapter had a total weight of 3.5 pounds, was 2.25 inches in length and 3.5 inches in diameter. He chose a simple coupling approach by fitting over the end effector locking pin on the tool mounting plate, guided by two indexing pins. The locking mechanism is a simple air cylinder actuated by a digital output point (Figure 2.3).

Exchange devices are still relatively new devices. Many industries use them throughout their manufacturing process but few companies actually manufacture them for resale. They are sold under a variety of names. Exchange device, quick change device and tool changer are the most common terms. Robo Hand Inc., PHD Inc., and Products For Automation are the primary vendors for these devices. Their devices come with both pneumatic and electrical connections, and a fail-safe locking mechanism. The payload capacity of these devices can range from below 100 pounds to over 2000 pounds. 


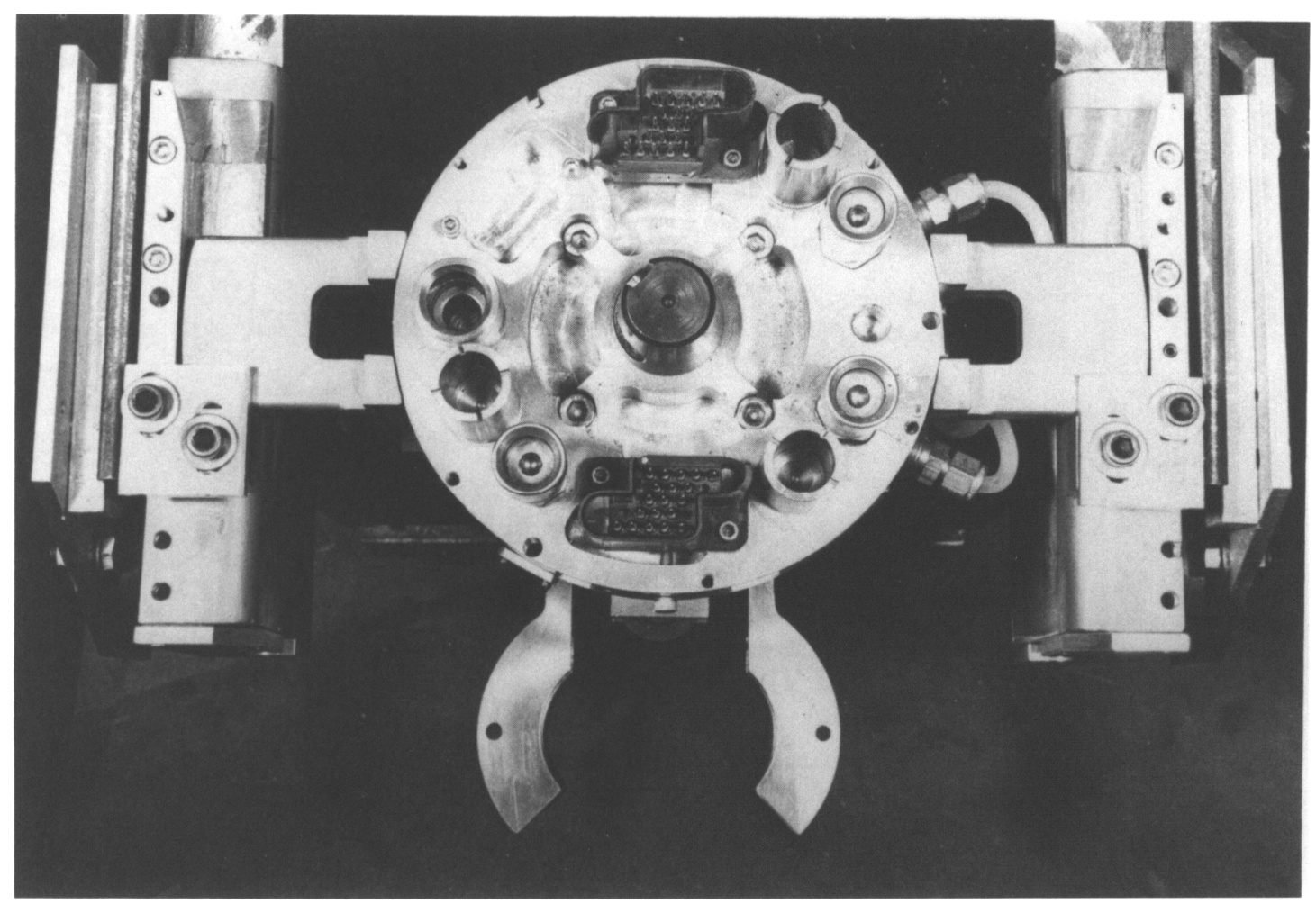

Figure 2.2 Gripper Ears--NBS 


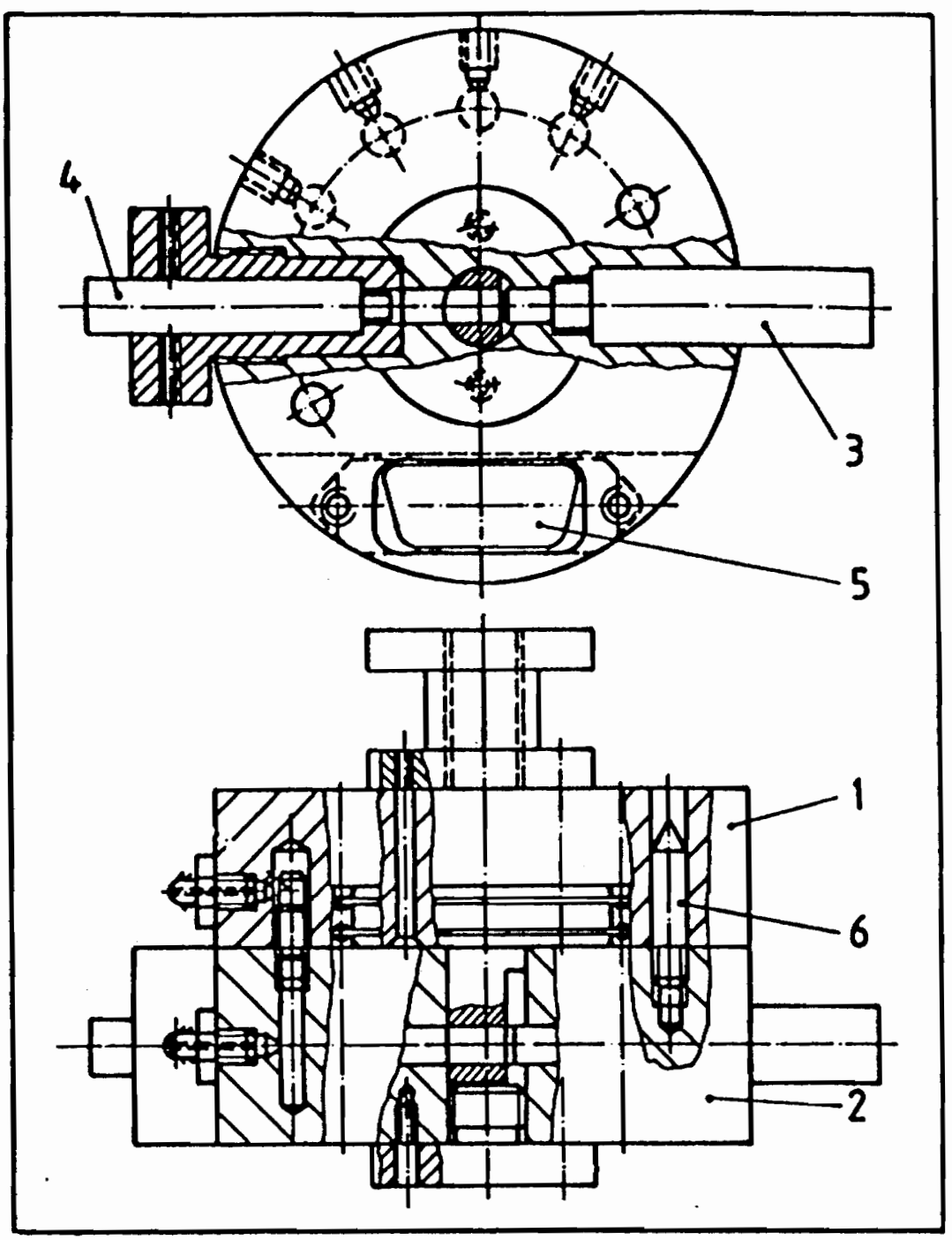

1. Lower Body (attaches to end effector)

4. Detaching Air Cylinder

2. Upper Body (attaches to robot wrist)

5. Electrical Connectors

3. Air Cylinder

6. Indexing Pins

Figure 2.3 Mertens' Quick Change 


\subsection{CONTROL SYSTEMS}

Teleoperation is the use of a robotic device which has mobility, manipulative and some sensing capabilities, and is remotely controlled by a human operator. Control of a teleoperated manipulator is either in a manual or computer control mode. The human operator is the limiting factor in the information and control environment of a remote controlled robot due to the limited input and output capabilities of humans.

Martin and Hamel [16] give a history of teleoperator development. They concentrate on the fundamental control structure. Since teleoperators offer real time interaction between the human operator and the manipulator, man can operate in unstructured environments and react to unexpected events. The authors state that the most common form of teleoperator interface is the replica master arm. Three forms of master controllers exist: (1) replica master -- normally 1:1 in geometric proportion, (2) switch box control -similar to pendant controllers, and (3) joystick control. Joystick control is superior to switch box control because movement can be accomplished through coordinated motions made using computer guidance. Replica masters still hold certain advantages in efficiency due to their ability to provide force reflection to the operator.

Babcock and Barhen [3] look at intelligent control systems operating in unstructured environments. They show that the major differences between force-reflecting teleoperators and industrial robots are: (1) teleoperators are usually designed with backdrivable actuation to allow the motors to generate forces as a function of position errors between master and slave joint angles, (2) inertias are minimized by mounting motors remotely in a centralized location away from the joints which they drive, and (3) 
stiffness is reduced by the emphasis on minimal inertia at the expense of frequency response and open loop positioning accuracy. Of course, the simplest control system is open loop control where no feedback from the manipulator is used. Open loop control is not commonly used today where intelligent manipulators are typical. Independent joint torque control is the simplest form of feedback control.

\subsection{SUMMARY}

The present Army EOD robot is an ineffective, primitive device. It offers no flexibility to changing situational demands. The robot was intended for use against improvised explosive devices and should therefore be capable of handling devices with a variety of shapes and sizes. Since the environment is unstructured, teleoperation is necessary for the majority of operations, but tasks which are repetitive through identical sets of moves should be taken out of the operator's control. With all the operational and mechanical faults of the SEOD robot, EOD technicians would prefer to handle the devices manually rather than use a system that doesn't work as it was intended.

The failure of the U.S. Army to take advantage of strides made in industrial automation seems to be the largest single shortcoming. There is a wide diversity of industrial end effectors in use in today's factories that could be incorporated into military projects such as the SEOD robot and RCT Rover. Since the objective is to improve the capabilities of EOD robots, the lifting capability of all end effectors must be equal to or greater than twenty pounds at maximum reach, the exchange device has to mate reliably and stay locked in the event of a power outage, and the control system has to be capable 
of switching from teleoperated to autonomous control and back again and position the exchange device accurately with relation to the end effectors. 


\section{CHAPTER THREE \\ ROBOT COMPONENT ANALYSIS}

When technology already exists, it does not have to be developed. Therefore, when a new research and development program is underway it is beneficial to look at current commercially available equipment rather than taking the time to try to develop new technology. In some instances modifications may be required to make the equipment robust enough for military use. The idea of an effective acquisition process is to get the best equipment to the customer as quickly as possible and as cheaply as possible. In this way total acquisition costs are reduced. The research progressed with that goal in mind. The following vendors were considered in the selection of the exchange device and end effectors: Products for Automation, Mack Corporation, PHD Inc., Robo Hand Inc., and Zaytran Inc. The following criteria were taken into consideration when selecting the equipment: (1) the task to be performed, (2) its weight, (3) compatibility with the other equipment, and (4) cost.

\subsection{IMPROVISED EXPLOSIVE DEVICES}

The FBI Bomb Data Center collects and tabulates information concerning bombing incidents which occur in the United States, the U.S. Virgin Islands, Puerto Rico, and Guam from public service agencies, the Postal Inspection Service, the Bureau of Alcohol, Tobacco and Firearms, and U.S. Military Explosive Ordnance Disposal Teams. To be classified as a bombing incident, the suspect device has to be classified as either an actual 
or hoax device. A hoax device is determined by the intent of the criminal. If the intent was to defraud or frighten the recipient then, the device is labeled a hoax. This differs from "suspicious packages" where no criminal intent is meant. Examples of "suspicious packages" are unclaimed luggage and briefcases which have been inadvertently left by their owners. Army bomb technicians respond to many "suspicious packages". These have to be treated as an actual device until it is determined otherwise. The majority of these packages are briefcases. Table 3.1 shows the number of bombing incidents for the last ten years. According to the Bomb Data Center there were 2499 bombing incidents involving 3551 improvised explosive devices in 1991. Explosives were used in seventyeight percent of the incidents with incendiaries accounting for the remaining twenty-two percent. An explosive bombing is an illegal detonation of a device constructed with high or low explosive materials. An incendiary bombing is the ignition of a device constructed with flammable materials designed to produce a burning effect. The devices were "successful", defined as either detonating of igniting, in seventy-nine percent of the bombing incidents. "Explosive devices detonated as planned eighty percent of the time and incendiary devices ignited seventy-six percent of the time."[5] Pipe bombs accounted for forty-four percent of the reported IEDs for a total of 1563 devices. The second most prevalent type of container was paper, tape or cardboard. A breakdown of the reported devices by container and filler is found in Table 3.2. The majority of the devices were initiated by a fuse or other type of burning delay or wick.

Pipe bombs are constructed of steel or PVC pipe with screw on end caps. Some have been found up to a foot in length. They are filled with smokeless powder one third of the time. Black powder constitutes the filler twenty-six percent of the time and some other unspecified low explosive is the filler twenty-one percent of the time. The maximum 


\begin{tabular}{|c|c|c|c|c|c|}
\hline $\bar{\sigma}$ & 芯 & $\stackrel{n}{n}$ & જु & $\stackrel{\circ}{\dddot{m}}$ & 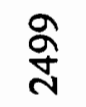 \\
\hline ริ & $\vec{\alpha}$ & 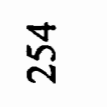 & స్ల & $\stackrel{9}{9}$ & $\underset{\sim}{\infty}$ \\
\hline के & F & 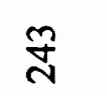 & ๙్̊ & $\bar{a}$ & ర్తి \\
\hline$\stackrel{\infty}{\infty}$ & مิ & $\vec{\Phi}$ & $\stackrel{\circ}{n}$ & q & 今ิ \\
\hline$\stackrel{\infty}{\infty}$ & 8 & $\Phi$ & $\stackrel{\square}{\circ}$ & $\mathcal{F}$ & $\stackrel{\infty}{\infty}$ \\
\hline$\stackrel{\circ}{\infty}$ & $\stackrel{\circ}{\circ}$ & $\Phi$ & స్తి & $\stackrel{\infty}{\sim}$ & $\underset{\infty}{\infty}$ \\
\hline$\infty$ & 㔯 & $\stackrel{\varrho}{=}$ & 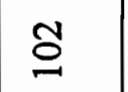 & in & 离 \\
\hline$\underset{\infty}{ \pm}$ & $\stackrel{\infty}{n}$ & $\stackrel{\infty}{=}$ & $\widehat{\Xi}$ & q & ఇి \\
\hline$\ddot{\infty}$ & $\mathscr{q}$ & 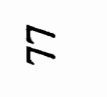 & $\grave{\Xi}$ & $F$ & ద్ర \\
\hline$\stackrel{\infty}{\infty}$ & $\underset{\substack{\infty \\
\infty}}{ }$ & $\approx$ & ¿ & i & $\stackrel{\alpha}{\alpha}$ \\
\hline$\Phi$ & $\hat{\sigma}$ & $\alpha$ & $\frac{n}{m}$ & $\stackrel{\infty}{\circ}$ & $\stackrel{\mathcal{Z}}{\Xi}$ \\
\hline & 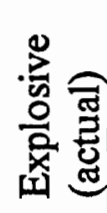 & 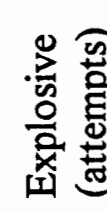 & 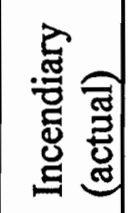 & 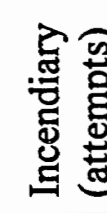 & 吾 \\
\hline
\end{tabular}




\begin{tabular}{|c|c|c|c|c|c|c|c|c|c|c|c|c|}
\hline 量 & $\stackrel{\overbrace{}}{\dddot{2}}$ & $\frac{a}{m}$ & 8 & $\infty$ & $\infty$ & $\nabla$ & స్ల & $\tilde{8}$ & $\widetilde{\sigma}$ & $\tilde{N}$ & $\stackrel{\infty}{\infty}$ & $\overline{\tilde{n}}$ \\
\hline $\begin{array}{l}\text { है } \\
\text { : } \\
\text { : }\end{array}$ & ఇু & $\Rightarrow$ & r & 은 & $\nabla$ & - & 요 & ષ্ & - & 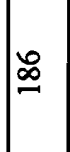 & $\stackrel{m}{m}$ & ชัర্ঠ \\
\hline 总 & 유 & $\cong$ & $n$ & $r$ & - & - & $\vec{\sim}$ & $\approx$ & 0 & $n$ & $\sim$ & $\infty$ \\
\hline 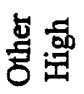 & $m$ & $N$ & - & 0 & $\sim$ & - & $m$ & $=$ & $\bar{N}$ & a & $m$ & 8 \\
\hline 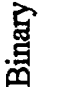 & 0 & $m$ & 0 & - & 0 & 10 & 0 & $m$ & - & 0 & - & a \\
\hline 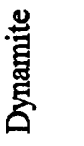 & 으 & - & 0 & - & $\sim$ & 0 & $m$ & 0 & ন্ & - & 0 & 요 \\
\hline 它点 & $\cong$ & $\approx$ & a & $\approx$ & $\sim$ & - & $\infty$ & $\mathbb{N}$ & - & 0 & શิ & $\vec{F}$ \\
\hline 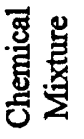 & $\sigma$ & $\exists$ & 0 & $F$ & 0 & 0 & $N$ & - & - & $\sigma$ & 0 & $\hat{\mathbb{N}}$ \\
\hline 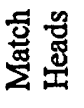 & m & - & 0 & $m$ & 0 & 0 & $m$ & 6 & 0 & - & 0 & $\underset{\sim}{\infty}$ \\
\hline 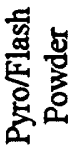 & $\approx$ & $a$ & $\cong$ & 유 & $\sim$ & 0 & নి & $\overrightarrow{\mathcal{F}}$ & $\nabla$ & r & $\approx$ & $\frac{ \pm}{6}$ \\
\hline 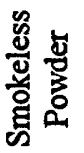 & $\stackrel{\infty}{\circ}$ & $\approx$ & $\infty$ & 2 & - & 0 & $F$ & ले & - & - & $\bar{\sigma}$ & $\bar{\nabla}$ \\
\hline 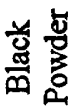 & gे & $\stackrel{\bullet}{\circ}$ & \pm & $\bar{m}$ & $\nabla$ & 0 & $g$ & g & 0 & $\simeq$ & $\vec{N}$ & $\tilde{c}$ \\
\hline 莺 & 总 & 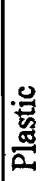 & 莺 & 总 & 啇 & 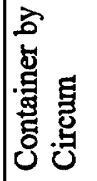 & 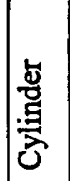 & 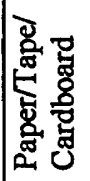 & 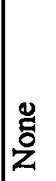 & 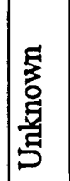 & 密. & 离 \\
\hline
\end{tabular}


weight of a pipe bomb a foot in length would be around five pounds. Briefcases are generally rectangular in shape and constructed of hard plastic, but some are found to have soft leather sides. The soft satchel type briefcase is more common in European countries. With either type, a single carrying handle is centered on top. Briefcases would normally contain high explosives -- dynamite or a plastic explosive. If a normal size briefcase was filled to capacity it would weigh around twenty pounds. Plastic containers are used in many incendiary devices. They are usually discarded milk jugs, bleach containers, and the like and so could be with or without handles. Cans and canisters usually contain some type of low explosive like black or smokeless powder. Coffee cans are a good example of this type of device. Bottles and jars are also very popular as incendiary devices. They can range from soda bottles to mayonnaise jars to large gallon bottles. The smaller sizes are discovered the most often and seldom have handles. Boxes are self-explanatory. They come in many sizes and can contain just about anything. A house filled with gas or a car loaded with explosives are examples of containers of circumstance. These so called containers are not encountered very often. Cylinders are normally filled with black powder or other low explosive. They can be metal or nonmetallic and are usually without handles. Paper, tape, and cardboard are used as wrappers to conceal the contents of a device and to hold it together. The contents are most often pouches of flash powder. Often when dealing with a high explosive device it will be open to view with no container. Sticks of dynamite taped in a bundle are a common example. When a military device is used as an improvised device it is normally a hand grenade or simulator of some type. They are filled with black powder, smokeless powder, or flash powder.

Unless the container was a container of circumstance, an improvised device would normally weigh less than twenty-five pounds. A worst case scenario confronted by a 
robotic vehicle is a device which is under some other object such as a desk or car. These are restrictive spaces that the robot has trouble reaching under and which the operator has trouble viewing through the robot's cameras. Devices contained within boxes or other containers that have large, flat surfaces with no handles are the most difficult packages for a robot to attempt to pick up because there is nothing on the package for the robot to grasp.

\subsection{END EFFECTORS}

End effectors are devices which pick up or otherwise handle objects for transfer or processing. They come in all types and sizes. Fingered grippers are simply pliers with the capability to grip internally as well as externally. Two fingered grippers simulate the motions of the thumb and index finger for reaching into channels, grasping parts within confined space or picking up any object of simple geometry. Three finger grippers duplicate the motions of the thumb, index finger and a third finger for grasping bodies of revolution and objects of spherical or cylindrical shape. Many stock grippers are supplied with blank fingers or with provisions for attaching blanks to finger motion elements. Finger blanks are then easily contoured to fit a work piece.

With improvised explosive devices varying so much in size and geometry, the ability to effectively handle all cases is limited with the choice of only one gripper. Having a choice of grippers allows the robot and operator to deal with objects that it encounters on the way to the suspect device (i.e. closed doors). Moreover, EOD technicians would have the opportunity to train with all the end effectors and determine which one they feel more 
comfortable using in the majority of situations. If the chosen gripper fails to perform as desired, the operator has available other grippers in the arsenal which can be used against the device.

In order to accommodate a wider variety of end effectors the robot should have both electrical and pneumatic power. On the current vehicles, electrical power is already supplied by the on-board batteries. Pneumatic power could be supplied by placing an air cylinder on board. The air cylinder is charged by an air compressor when the robot is not in use, similar to the charging of the robot's batteries. Electrical power permits the employment of a magnetic gripper and pneumatic power provides the gripping force for the fingered grippers. The addition of pneumatic power widens the field of commercially available grippers. Grippers that work solely on electric power do not have the lift capacity of pneumatic grippers.

Based upon the selection criteria that each gripper be lightweight and capable of lifting at least forty pounds and keeping the total number of end effectors to a minimum due to a restriction in available space, four end effectors have been chosen. Three grippers operate on pneumatic power and one on electric power. Technical drawings of these grippers can be found in the appendix. Experimentation with these grippers to verify their applicability is necessary. A research project testing different end effectors is needed to develop a set of specifications for grippers used on EOD robotic vehicles. Special onetime-use grippers may be ideally suited for this type of application. With the resulting design specifications, design changes to the chosen end effectors and/or a reduction in the number of end effectors may be warranted. 
Products for Automation offer a lightweight, compact vacuum gripper. The VGC 100 features adjustable grip sense and contact sense, an optimal integral vacuum generator, easy interfacing, and a high payload capacity. A range of cup size from 0.28 inches to 4.41 inches in diameter is available. A 3.03 inch cup size is recommended. It can obtain a seal on the majority of the devices that it will be used against. It also has the diameter to lift heavier packages. A twenty-five pound lift would only require 3.5 PSI and a forty-five pound lift would need 6.2 PSI. This gripper weighs 0.28 pounds.

Mack Corporation markets the Series II BASE two and three fingered angular grippers. These grippers feature a self centering trait with repeatability within a few thousands of an inch. Standard internal or external fingers are available or a blank version which can be modified to any configuration can be provided. Fingers are easily interchanged in all Series II BASE grippers of like style and size. Two inch fingers are recommended for both the two and three-fingered gripper. The two-finger design incorporates both internal and external gripping surfaces. The external gripping surface is a good general purpose grip capable of picking up a variety of objects. Devices with recessed surfaces are picked up with the internal gripping surface. The three-finger gripper has curved fingers with only an external gripping surface. This gripper is used for revolute objects to control rotation and can supplement the two-finger gripper. The shape of the gripper fingers are shown in the appendix. These grippers weigh approximately 9 ounces.

Magnetic end effectors are not found as part of the commercial market, however, end effector vendors regularly design them for customers. The design for this gripper requires an electro-magnet capable of being turned on and off. The magnet should be 
pliable so when it contacts surfaces that are not completely flat it can deform to place more of the object's surface area in contact with the magnet. This can be accomplished by adding a cushion of metal filings between the magnet and the gripper base. The metal filings allow the magnetic field to propagate through them to the magnet without significantly subtracting from the magnet's strength and they give the magnet some flexibility. The magnet should be capable of lifting forty pounds and be no more than 2.50 inches in diameter.

Table 3.3 shows a matrix of possible gripper selections according to the IED container. It is difficult to say without question that a specific gripper will work all the time on a container made of the same substance because of the multitude of configurations. The utilization matrix is by no means the final authority on which gripper should be used. In the end it is the operator who will make the final decision based on the situation and the operator's training and personal preference.

\subsection{EXCHANGE MECHANISM}

The decision then to use multiple end effectors brings to contention the debate of whether to bring the robot back to the safe area to physically change end effectors or to use an exchange device and automatically change end effectors while the robot is still downrange. Without question, the ability to change end effectors automatically is more efficient -- saving both time and labor. The SEOD robot trails a fiber optic cable as it moves, returning to the point of origin often means traveling backwards, especially indoors. Due to the increased difficulty in this maneuver, it usually takes longer to return 
TABLE 3.3. END EFFECTOR UTILIZATION

\begin{tabular}{|l|c|c|c|c|}
\hline $\begin{array}{c}\text { Container/ } \\
\text { Gripper }\end{array}$ & $\begin{array}{c}\text { 2-Finger } \\
\text { Gripper }\end{array}$ & $\begin{array}{c}\text { 3-Finger } \\
\text { Gripper }\end{array}$ & $\begin{array}{c}\text { Vacuum } \\
\text { Gripper }\end{array}$ & $\begin{array}{c}\text { Magnetic } \\
\text { Gripper }\end{array}$ \\
\hline Pipe & $\mathrm{X}$ & $\mathrm{X}$ & & $\mathrm{X}$ \\
\hline Plastic & $\mathrm{X}$ & $\mathrm{X}$ & & \\
\hline Can/Cannister & $\mathrm{X}$ & $\mathrm{X}$ & & $\mathrm{X}$ \\
\hline Bottle/Jar & $\mathrm{X}$ & $\mathrm{X}$ & & \\
\hline Box & & & $\mathrm{X}$ & \\
\hline Container by Circum & & & & \\
\hline Cylinder & $\mathrm{X}$ & $\mathrm{X}$ & & $\mathrm{X}$ \\
\hline Paper/Tape/Cardboard & $\mathrm{X}$ & $\mathrm{X}$ & $\mathrm{X}$ & \\
\hline None & $\mathrm{X}$ & $\mathrm{X}$ & $\mathrm{X}$ & \\
\hline Unknown & $?$ & $?$ & $?$ & $?$ \\
\hline Military Device & $\mathrm{X}$ & $\mathrm{X}$ & & $\mathrm{X}$ \\
\hline
\end{tabular}


to the safe area. The RCT Rover is capable of turning 360 degrees but traveling back to the safe area still takes up time that would be better spent working downrange.

The design requirements for the exchange mechanism were that it (1) must be capable of supporting the power requirements of the end effectors, (2) have a lift capacity of at least 45 pounds, (3) be lightweight, (4) have a fail safe locking mechanism, and (5) have repeatability of mating. Four end effectors have been chosen. Three require pneumatic power and one uses electrical power. The Mack fingered grippers operate at 80 PSI but have a maximum operating pressure of 150 PSI. In order for the vacuum gripper to adjust its contact and grip sense it needs $115 \mathrm{VAC}$ at $1.6 \mathrm{amps}$ or $24 \mathrm{VDC}$ at 1 amp. Electrical power also provides the signal passing capability necessary for sensor feedback. In the future the operator may like to know when the lift capability of the manipulator system is being exceeded or how much force is being applied by the gripper or even how close the gripper is to the device. Modifications to add these types of sensors would require electrical power to be present.

Robo Hand Exchange Model RHC 1 is a lightweight tool changer designed to withstand the stress of heavy payloads. It weighs only ten ounces but can withstand a payload of 125 pounds. The Robo Hand changer provides both pneumatic and electrical connections. The changer has a fail-safe locking mechanism that stays locked even with loss of air pressure. The strength of the locking mechanism is due to the seven degree cone angle of the mechanism itself. The friction between the balls and retainer, and the piston and bore is enough to withstand the maximum payload without uncoupling regardless of the status of the power source. It positions itself, seats and locks accurately, even when the two halves are initially misaligned. The RHC 1 features separate 
positioning and locking mechanisms for long term accuracy and consistency. The technical data for the RHC 1 is found in the appendix.

\subsection{CONTROL SYSTEM}

When planning for the control system of a robot, an evaluation of known data is necessary. In order to have autonomous control, the robotic device must have a stored representation of the world in which it exists or the capability of obtaining that information through sensor processing and scene analysis. In the case of the EOD robot, its world is constantly changing. However, the set of motions to exchange grippers will be the same repetitive movements every time. Once the robot is programmed to go to a known 'home' location, it knows the geometry of its world. Since the location of the stored grippers is unchanging, the gripper exchange sequence can be done in autonomous control.

Both the SEOD robot and RCT Rover are teleoperated systems. Due to the unstructured environment in which EOD robots work, the system needs to remain teleoperated. The end effector exchange sequence is a set of moves to and from known positions. To do the exchange by teleoperation is difficult. The operator only sees what the camera mounted on the robot is focused on. This means that the operator sees the end of the manipulator but not anything on the periphery. Depth perception is virtually nonexistent. To make the connection between the robot adapter and the tool adapter consistently and without damaging either the exchange mechanism, end effector, or tool holder is formidable. Making the exchange under autonomous control is simple since the 
geometry and motions are known. Neither the SEOD robot or the RCT Rover have feedback from the robot's arm, shoulder, wrist, or gripper going to the controller.

To allow for both autonomous and teleoperated control, a separate parallel processor is suggested. Since the RCT Rover uses Brush-type DC motors, all the joints are rewired to use their own amplifiers and a path for position feedback is added. These wires are then connected to the robot controller where a separate computer card is added to control the autonomous operations. The autonomous computer card plans the path kinematics, and controls the joints by sending digital signals to the individual amps and reading the feedback. These two cards, one that controls teleoperated motions and one that controls autonomous motions, and the controller's CPU communicate with one another. When a command is entered into the controller, the CPU reads the address location of the signal package to determine to which control board the message belongs. The exchange sequence controlled by the autonomous board has priority over all other commands. When it receives a signal to initiate the exchange sequence a flag in the register is raised that inhibits all other commands from being carried out while the exchange sequence is still in progress. This is a safety feature in case two or more switches are triggered at the same time. 


\section{CHAPTER FOUR \\ ROBOT SYSTEM INTEGRATION}

Now that all the equipment changes have been proposed it is important to ensure that all the components can work together as one system. The end effectors must all fit on board the robot. They must be situated so that they ride protected but remain accessible within reach of the robot arm. They also have to be secured in one position to guarantee repeatability of mating with the robot exchange adapter. Finally, the whole system must be controlled, with teleoperation and autonomous operations working in synchronization. The RCT Rover / ANDROS Mark V-A was used as the platform for proposed modifications.

\subsection{TOOL HOLDER}

In order for the end effectors to remain on board the robot between usage they must be placed in a tool holder. The tool holder must not only hold the tools but keep them secure. It was particularly important in this case since EOD robots are mobile and often travel over rough terrain. The tool holder has to be large enough to hold all four end effectors but designed so as to fit within the confined space of the robot. The selected placement of the tool holder is on the front of the robot body housing between the two tracks (chest of the robot). This area does not interfere with the movement of the robot arm or track system. The robot's arm can reach it's chest area by raising the shoulder joint. The camera mounted above the current gripper will probably have to be moved 
back slightly on the robot's arm to allow clearance for the exchange to take place. This will not adversely affect the picture taken by the camera. Since the body housing is a raw cast piece and not machined, the actual dimensions of the chest area might vary slightly but are approximately 13.875 inches wide and 4 inches high. The tool holder could not be any wider than 13.875 inches or it would obstruct the movement of the tracks. There are no obstructions to the top or bottom so the height of 4 inches could be expanded to accommodate the end effectors. Placing all four grippers in a row with buffer space between them exceeded the width of the chest area. Another design had to be developed. Circular and diamond shaped holders were considered but rejected due to the difficulty of supporting the holder and protecting the stored grippers during travel. Use of an indexing holder was rejected to keep electrical wiring and control issues minimized as well as to reduce the possibility of increased downtime. The design that was finally selected staggers the arrangement of the grippers.

Since the body of the ANDROS Mark V-A is cast, not machined, each robot has slightly different dimensions. The geometry of the working space will be specific to each robot. Each robot will have to be initially taught the set of moves needed to make the exchange possible.

Figure 4.1 shows an isometric view of the tool holder. The design has two metal plates separated by posts. The bottom plate is 13.50 inches wide and 4 inches high. This plate mounts directly to the robot's chest area. The top plate is 13.50 inches wide and 6 inches high. This plate has the slots in which the end effectors are stored. The two plates are separated by four -4 inch high posts. The area between the two plates is where the grippers will actually rest. There are four slots that will store the grippers. The grippers 


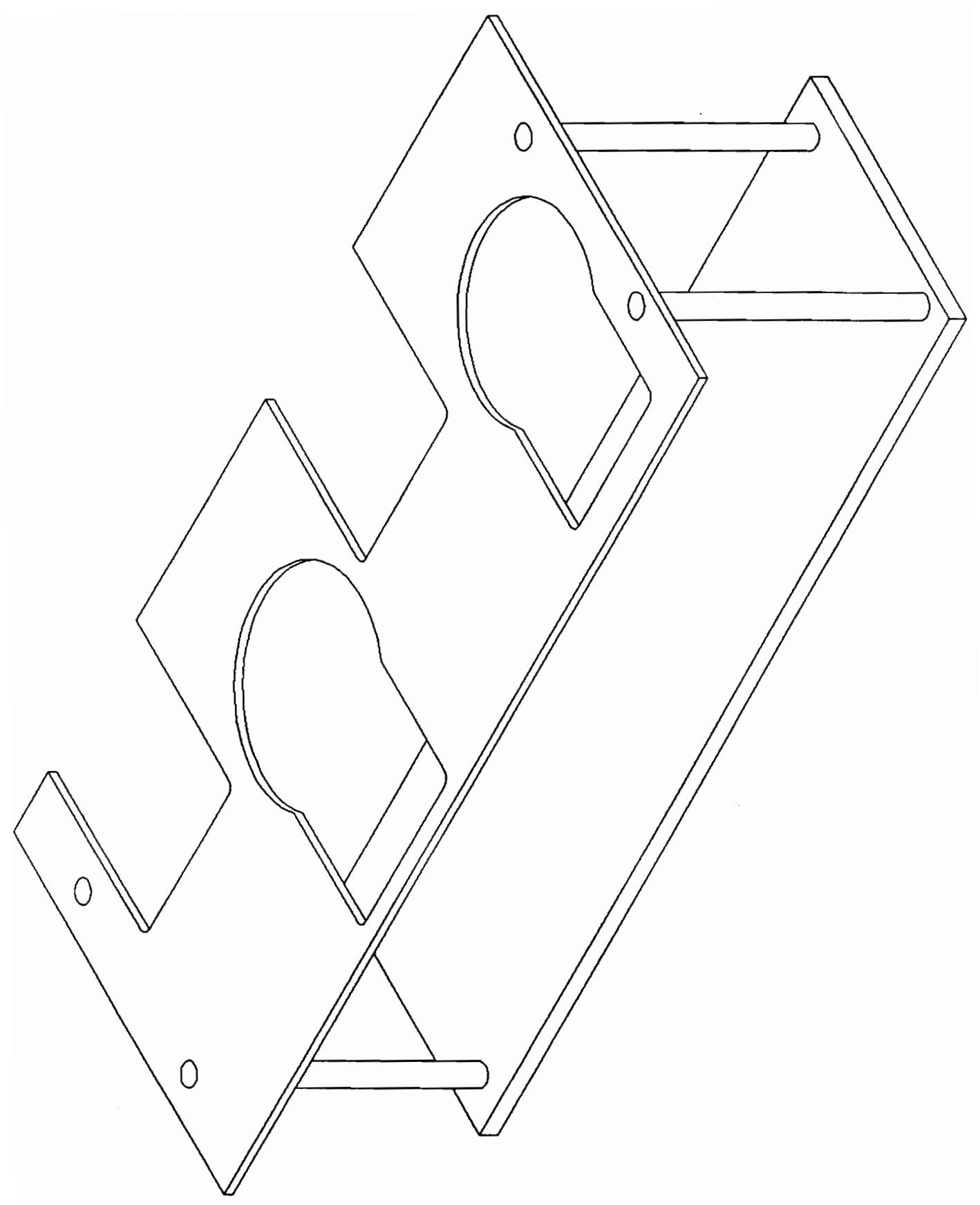

Figure 4.1 Tool Holder -- Isometric View 
will move to a position at the top of the slot and then slide down into the storage niche. The exchange device will face outward. The far right slot is smaller than the other three to accommodate the slightly smaller vacuum gripper. Figure 4.2 shows the top, right side, and front views of the tool holder.

Once the grippers are in the tool holder there has to be a method to keep them in place. A gripper that is allowed to bounce around during travel will possibly damage itself, the exchange adapter, or another gripper. It will also shift out of position, not allowing for reliable mating between the robot and tool exchange adapters. To solve this problem gripper ears are suggested. All the grippers need adapter plates to size them up or down to the diameter of the exchange device. These plates are modified to include ears that will secure the grippers in their slots. The ears are actually two pieces that fit one on each side of the top plate, providing a slot in which the plate will slide. The two piece design keeps the grippers from falling inward or outward and accurately positions them for exchange. Gravity will keep the grippers in their slots. The center circumference is squared on the half of the adapter that slides into the holder slot. This will keep the grippers from rotating when the robot is in motion and guarantee reliable mating of the exchange mechanism. Figure 4.3 shows the adapter plate with ears that will be used on the fingered and magnetic grippers. The adapter plate that is needed for the vacuum gripper has the same size ears and body length but the diameters of the steps are smaller due to the smaller size of the gripper and its need to be sized up. Figure 4.4 shows the adapter plates inside the tool holder. The grippers hang between the two holder plates with a .10 inch clearance above the bottom plate. 

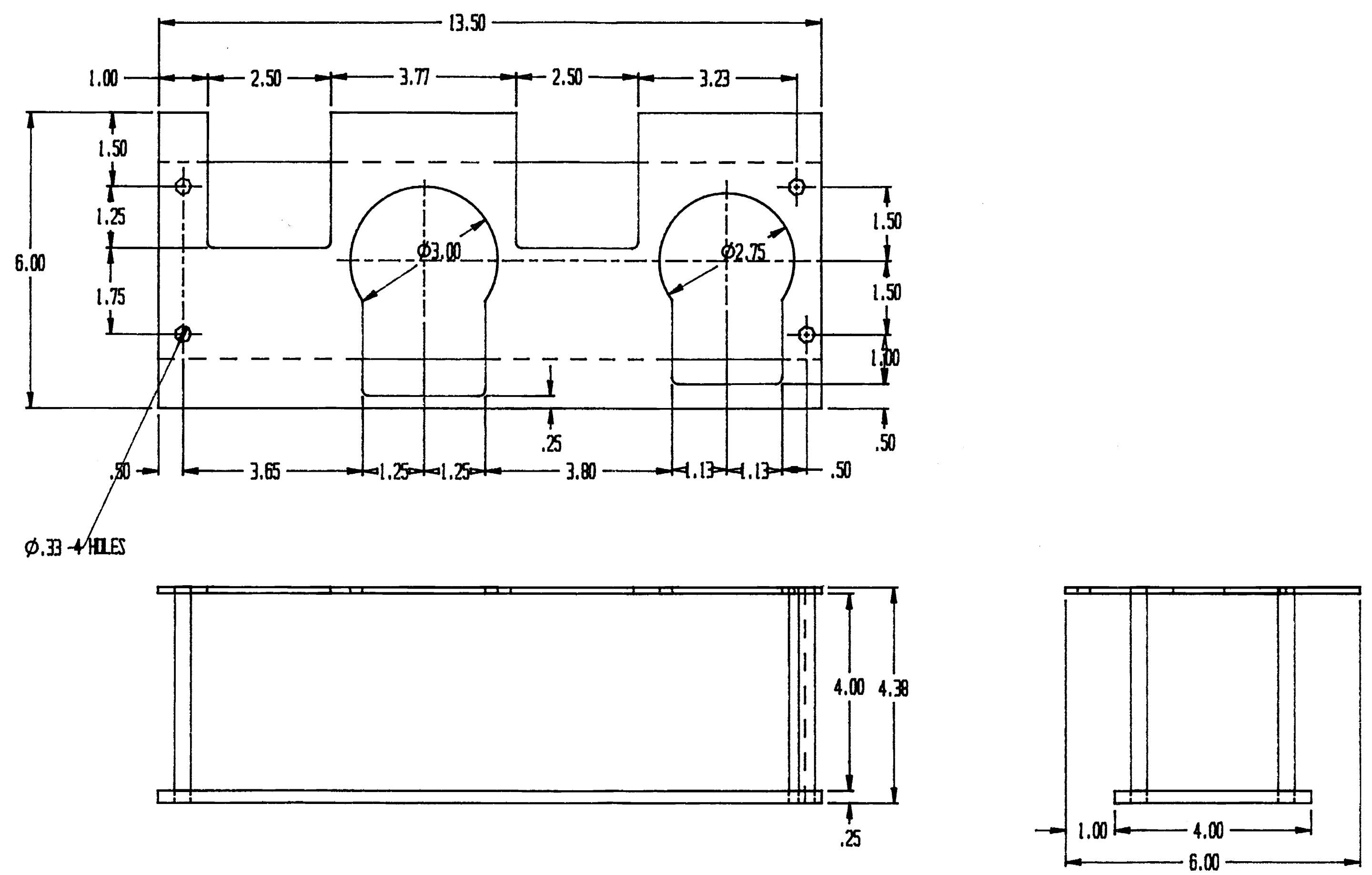

Figure 4.2 Tool Holder --Mechanical Drawings 

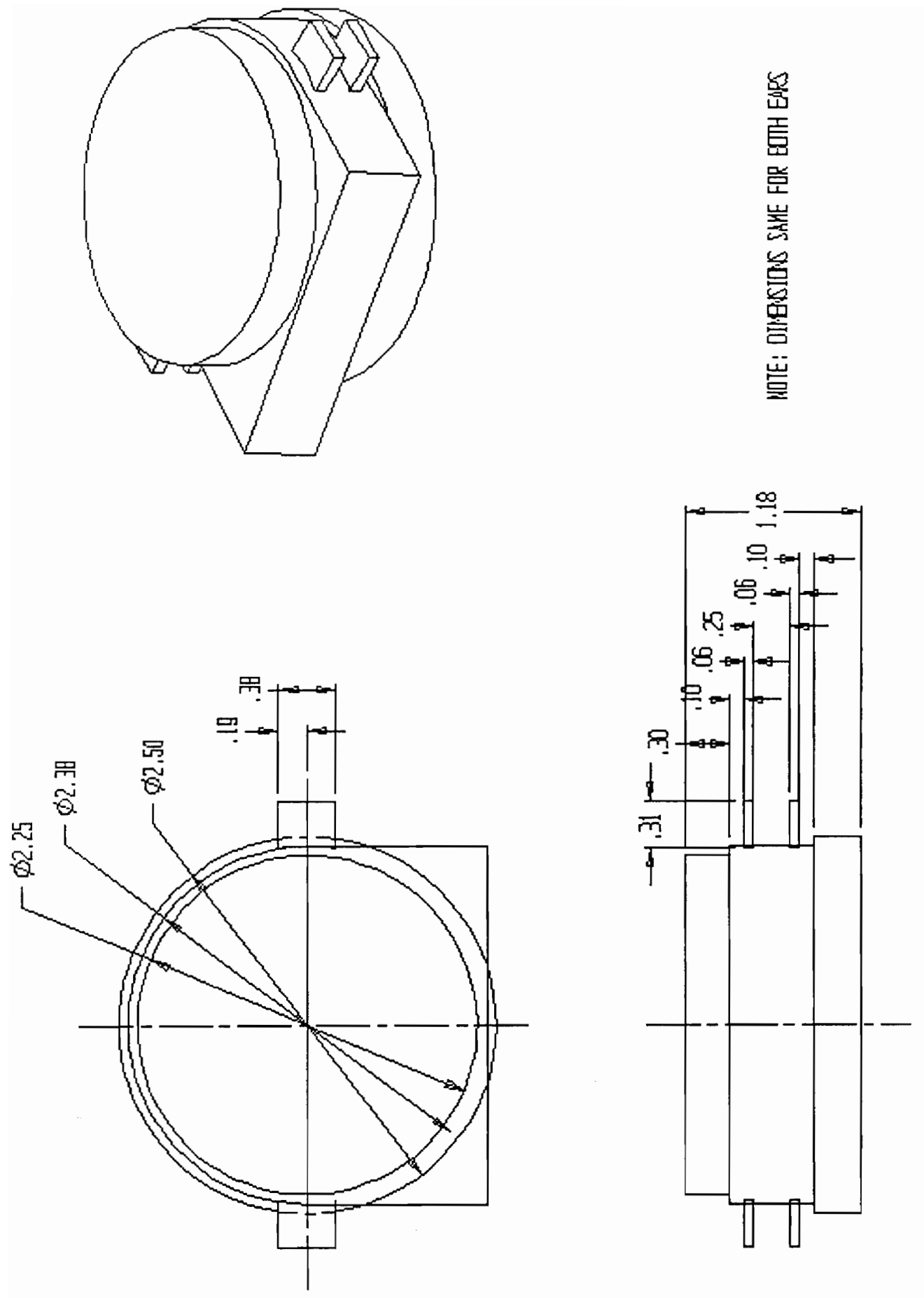

Figure 4.3 Gripper Adapter With Ears 


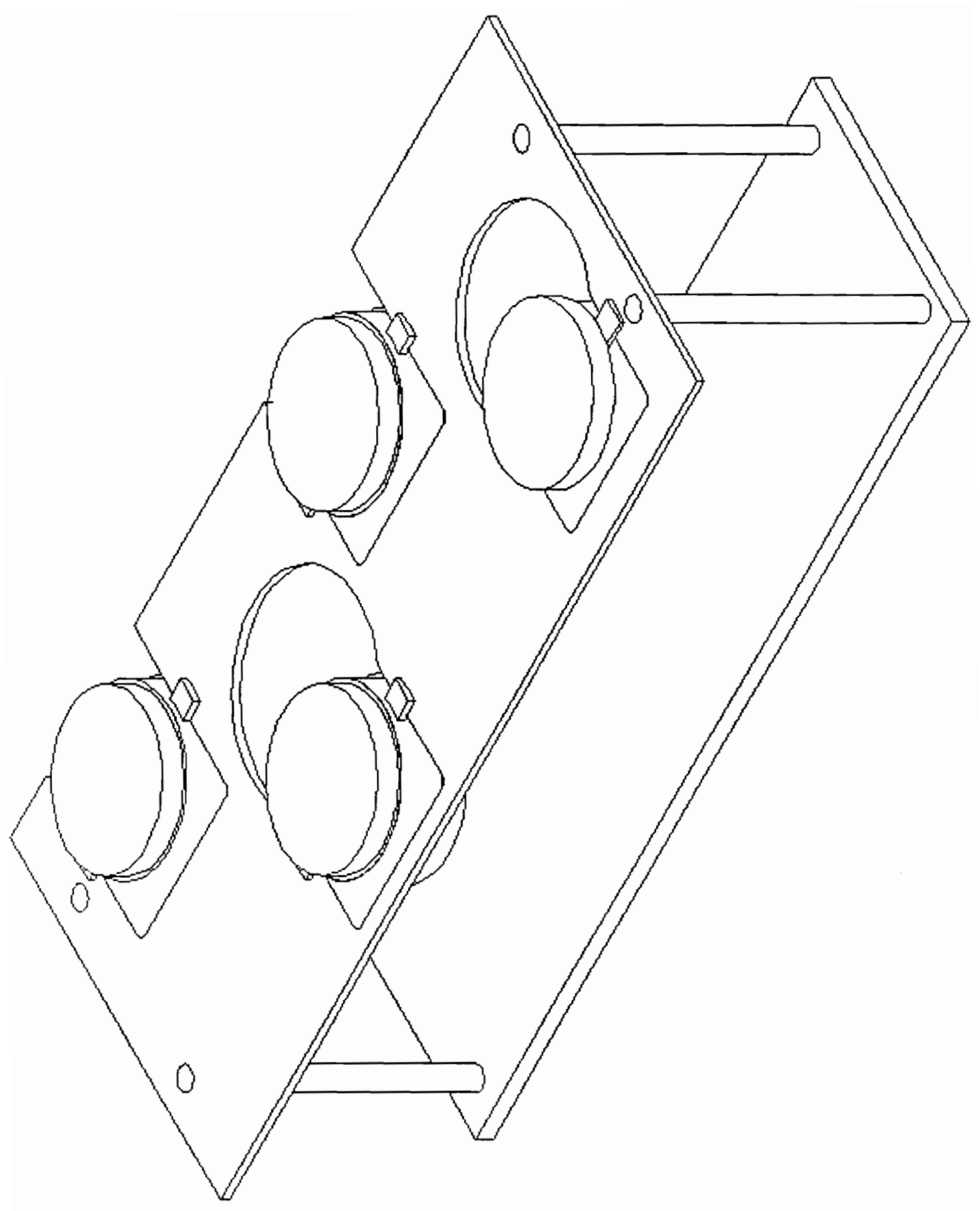

Figure 4.4 Tool Holder With Gripper Adapters 


\subsection{CONTROL SYSTEM}

The RCT Rover uses Brush DC motors to drive the tracks, manipulator joints, and cameras. The manipulator joints are wired through a single arm amp with a relay assigned to each individual joint. Figure 4.5 shows a functional block diagram of the Rover. In order to have autonomous control, feedback is needed at each joint. To accomplish this each manipulator joint must have its own amp with feedback from the motor. The feedback allows the robot controller to know the position of each joint in relation to its work space. Figure 4.6 shows a wire schematic of the proposed change. A second computer board is added to control the autonomous operations. A board already exists that controls the teleoperation motions. This second board will be the dominant board, although the two boards will have the ability to communicate with each other. All incoming signals are read by the robot controller CPU. The CPU knows the functions that the robot performs. By virtue of an address number affixed to the incoming command message, the CPU knows to which control board to pass the message. The priority of the boards is set with the autonomous control board having control in case two switches are hit simultaneously. Whenever the autonomous control board has control, a flag is raised in the register to inhibit all other devices from functioning. This precludes any movement of the robot while the gripper exchange sequence operates.

The equipment component selections made in the previous chapter and the design modifications stated above show that current industrial automation technology can be a viable force in the EOD Robotics Program. Exchangeable end effectors are a feasible modification to EOD robotic vehicles. 


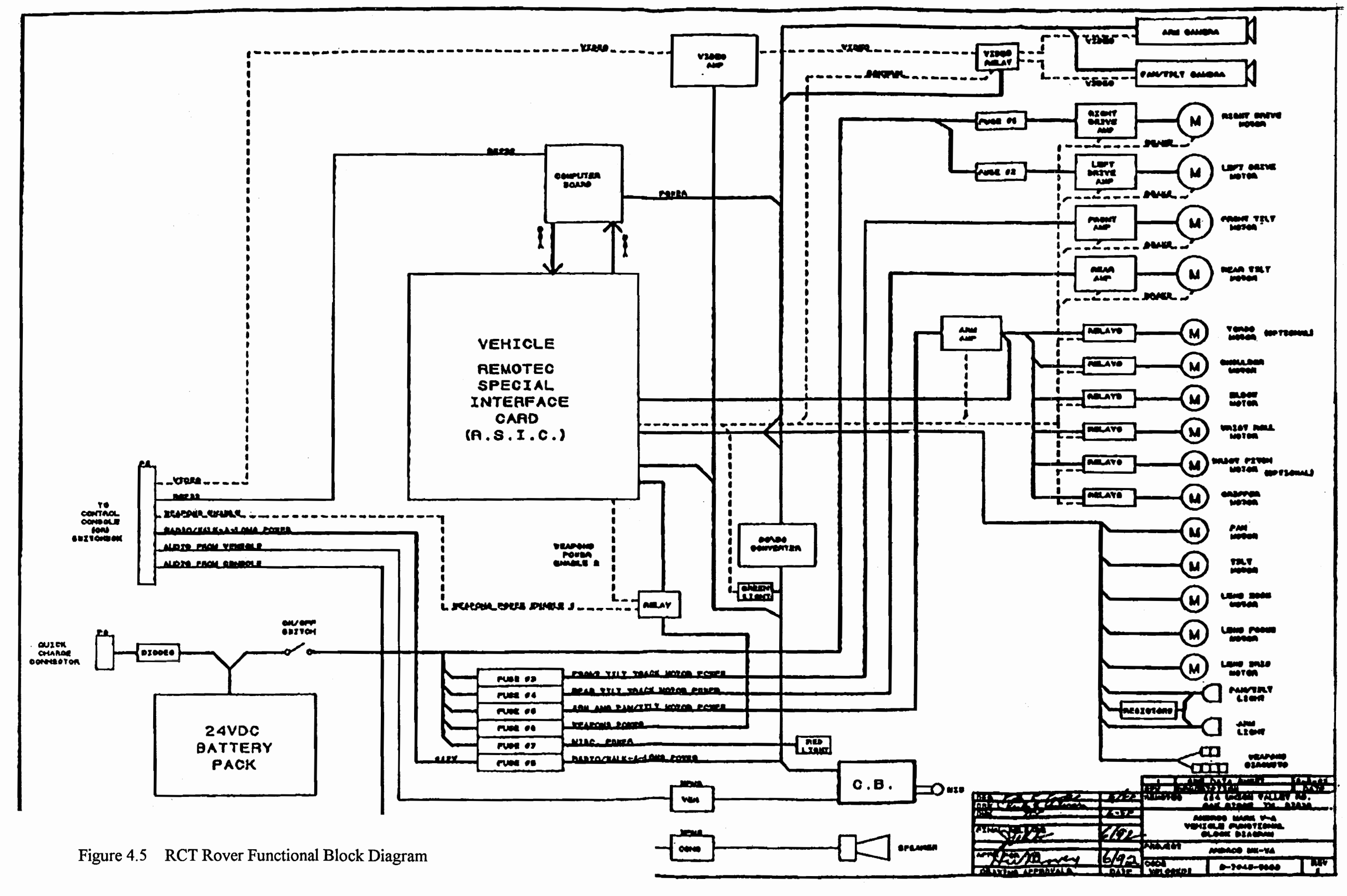




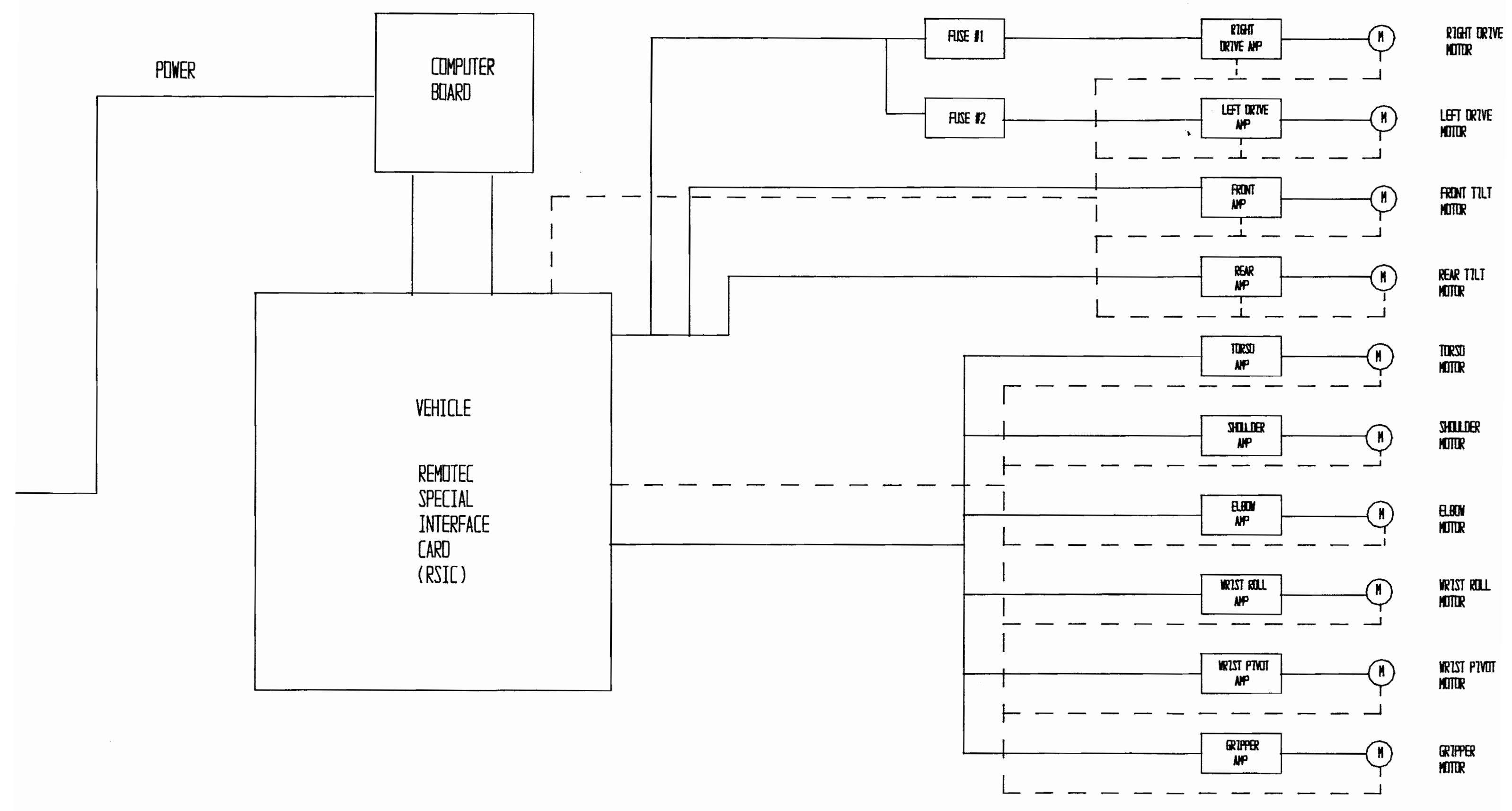

Figure 4.6 Autonomous Control Wiring Change 


\section{CHAPTER FIVE}

\section{SUMMARY AND RECOMMENDATION FOR FUTURE STUDY}

The objective of this research was to conduct a feasibility study showing the viability of using existing industrial automation technology on Army EOD robotic vehicles. The Security Explosive Ordnance Disposal robot and the RCT Rover were used as platforms for this research. Both robots are teleoperated, mobile systems which come equipped with a single gripper at the end of their arm. The robots work in unstructured environments against improvised explosive devices. A redesign of the tooling to allow for several exchangeable end effectors was proposed. The redesign incorporated commercially available products. Four end effectors were chosen based on their size and lift capability. It was necessary to select the minimum number of grippers that could handle the widest variety of package configurations. Space on board the robots was limited. Information from the FBI Bomb Data Center concluded that pipe bombs constitute the largest number bombing incidents. Paper, tape, and cardboard was the second most popular container, with plastic and cylinders coming in third and fourth. A two-finger and three-finger angular gripper was selected from Mack Corporation. These grippers were chosen for their ability to handle the majority of the devices found. A magnet gripper was suggested for use against metallic, irregularly shaped objects. This gripper has to be manufactured specifically for this purpose since magnetic grippers are not commercially available, although, end effector vendors regularly design them for customers. A vacuum gripper was selected from Products For Automation for use against packages with no lifting handles. 
In order to make the exchange possible a quick change mechanism was needed. The Robo Hand RHC 1 fit the design specifications of being lightweight with a large lift capability, having both pneumatic and electric connections, and mating reliably. Finally, a redesign of the control system was necessary to allow for both teleoperated and autonomous operations. Autonomous control was desired for the end effector exchange sequence. By adding amps to all the manipulator joints and feedback to their motors, position control of the gripper will be captured. By routing these wires to a separate control board and making this the dominant board, safe reliable communication between the two boards is possible.

Now that the feasibility of incorporating quick change technology has been shown, phases two and three should begin. In phase two a RCT Rover needs to be acquired for redesign and testing. As part of this testing a separate research project needs to be conducted. Different end effectors must be tested and a set of specifications for the gripper(s) developed. Once the Rover meets the standards set forth by the NAVEODTECHCEN, the robot needs to be fielded to test units in the field for further evaluation. If the new design passes the rigors of Army life, phase three will commence and the remaining EOD units will have their robots modified.

For future research, one consideration would be in the arena of vision systems. A vision system could be designed for EOD robotic vehicles that would provide all the position feedback necessary, eliminating the need for all the sensors and wiring. This technology is already being incorporated in the nuclear industry. 
A second research consideration for investigation is in the arena of sensors. The capture of sensor inputs for processing and analysis enables existing navigation and path planning algorithms to be utilized making possible the use of autonomous robots in unstructured environments. Expanding sensor feedback from the gripper and joints should be explored to discover precise positioning capabilities and gripper sensitivity for the object being grasped.

Finally, the area of intelligent grippers should be researched. Can intelligent grippers be made robust enough to operate in a hostile environment? Perhaps the development of an anthropomorphic gripper will make the need for an exchange device unnecessary. 
APPENDIX 


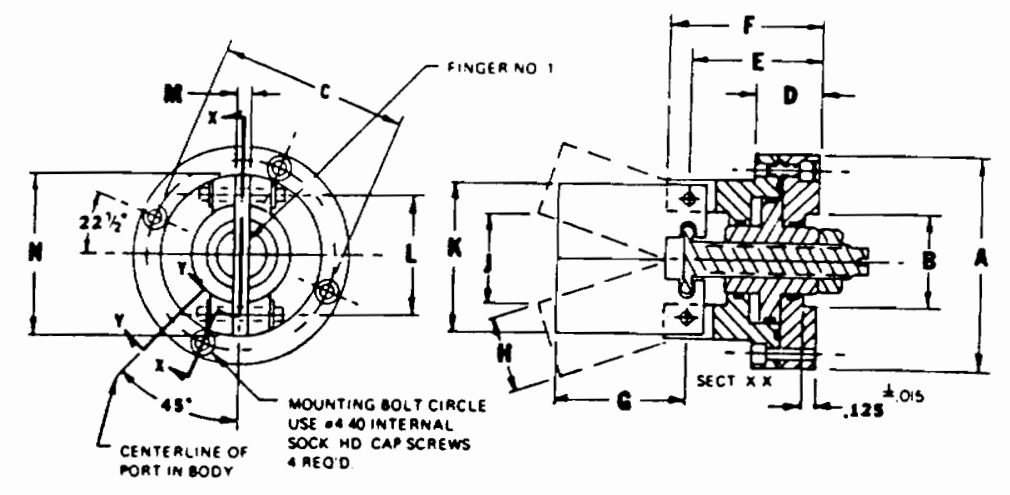

- Soft Dlonk fiagers

\begin{tabular}{|c|c|c|c|c|c|c|c|c|c|c|c|c|c|}
\hline Dant to & $=020$ & $=0.10$ & $\begin{array}{l}: 010 \\
c\end{array}$ & $: 000$ & $=000$ & $=000$ & $\begin{array}{c}=000 \\
c\end{array}$ & $\begin{array}{c}\mathrm{N} \\
\mathrm{M}\end{array}$ & ' & Nonor & $\begin{array}{c}=010 \\
1\end{array}$ & $:=08$ & $=000$ \\
\hline 1000 & 1500 & 0319 & 1850 & 0350 & ס: & 150 & 0 ses & 040 & 1050 & oors & $00 x$ & $0 \cdot \pi$ & 1000 \\
\hline$=1$ & 1500 & 0.500 & $1 \times 0$ & 050 & $1 \times$ & 1200 & 0013 & O M & $0.7 \times$ & Dex & ond & $0 x$ & 1000 \\
\hline$m$ & 2000 & ours & $1 \times 50$ & 000 & 10 & 1 & 1250 & 0 & 0.006 & 100 & תיי & 010 & 1500 \\
\hline 300 & 3500 & 13 & 2730 & 0502 & ניני & (4) & $1>0$ & .000 & 0 & 2000 & $16 x$ & - '. & 3000 \\
\hline
\end{tabular}

- SPECIFICATIONS

MATERIAL MIGN STRENGTH ALUMINUM ALLOY WITH STAINLESS STEEL PISTON A AOJUSTING STEM SEAUNG ELEMENTS STANDABD "O." AINGS IN BUNA "N COMPOUNO

SEALING ELEMENTS SIANOARD O RINGS IN BUNA N COWPOUNO

MaXimum OOE RATING TE MPE RATURE - $40^{\circ} \mathrm{F}$ to $350^{\circ}$

EXTERNAL FINISH STRIA TEX

EXTERMALL FINTSH STRIA TEX

T" DIAME TEA IS TME MOUNTING EOLT CIRCLE USE FOUA 9400 INTE RMAL SOCKEI HEAD CAP SCAEWS

- PINCH FORCE, GRIPPER WT. \& FINGER ROTATION

\begin{tabular}{|c|c|c|c|}
\hline GRIPPE R NUMBER R & $\begin{array}{l}\text { PINCM FOACE } \\
\text { AT FO PSI } \\
\text { APPPOXX }\end{array}$ & $\begin{array}{l}\text { GRIPPIA } \\
\text { MGIGAI } \\
\text { IAPPROXI }\end{array}$ & $\begin{array}{l}\text { ANGULAR } \\
\text { ROTATION OF } \\
\text { FINGE RS INOW }\end{array}$ \\
\hline $2000 \times 2000+2600$ & 4. & 200 & $2 x^{\circ}$ \\
\hline $7001.28005+2600$ & 5. & 40 & $26^{\circ}$ \\
\hline $2802.2606+2610$ & 16. & 600 & $1 x^{\circ}$ \\
\hline $2003.2601 . \times 11$ & 436 & 80 & $10^{\circ}$ \\
\hline
\end{tabular}

Two-Fingered Gripper--Model 2603 
- machiming stamdard for fingers

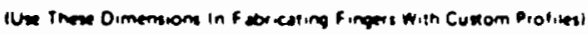

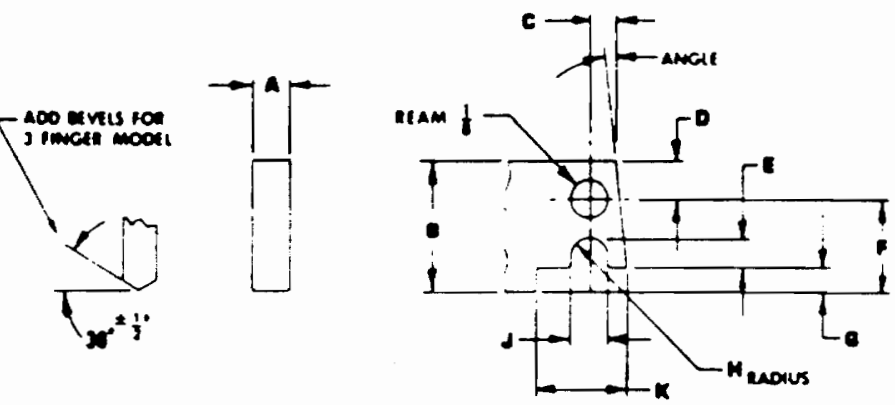

\begin{tabular}{|c|c|c|c|c|c|c|c|c|c|c|c|}
\hline $\begin{array}{l}\text { GRIPEE } \\
\text { PART NUMBER }\end{array}$ & $\pm \underset{4}{ \pm \infty 2}$ & $\begin{array}{c}\text { NOM } \\
0\end{array}$ & $\begin{array}{c}-\infty \\
c\end{array}$ & $\begin{array}{c} \pm \infty \\
0\end{array}$ & $=005$ & $\begin{array}{c}=\cos \\
1\end{array}$ & $\begin{array}{c} \pm \cos \\
G\end{array}$ & $\begin{array}{c}\text { NOM } \\
\text { H }\end{array}$ & $=002$ & 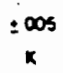 & Ando \\
\hline 260026002600 & 121 & 0438 & 125 & 125 & 100 & 313 & $\infty 2$ & 063 & 127 & 313 & $\infty$ \\
\hline 2001.2005 .2000 & 121 & 0469 & 125 & .125 & 100 & $3 m$ & 120 & 063 & 127 & 313 & $\infty$ \\
\hline 2002.200610 & 184 & 0719 & 156 & 156 & 150 & 563 & 200 & 0,3 & 127 & 375 & $\infty$ \\
\hline 2000.2007 .2011 & .14 & 1.000 & 190 & 156 & .100 & 813 & 219 & os & 100 & 500 & $7^{\circ}$ \\
\hline
\end{tabular}

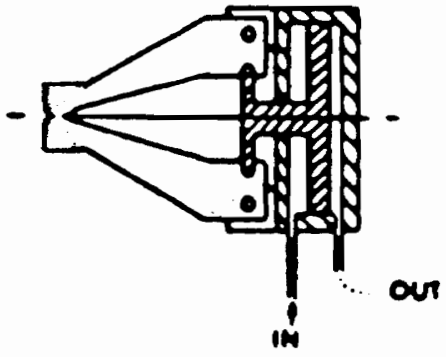

Two-fingered gripper finger design 


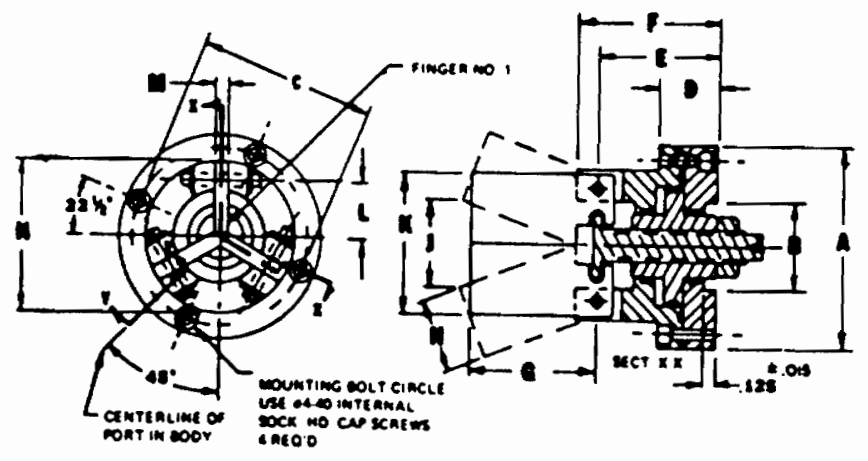

- Selt Dlank Fiagers

\begin{tabular}{|c|c|c|c|c|c|c|c|c|c|c|c|c|c|}
\hline pant no & $: \infty$ & $=010$ & $\begin{array}{c}=010 \\
c\end{array}$ & $=00$ & $=\infty$ & $=\infty$ & $=\infty$ & n & 1 & 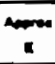 & $=\infty$ & $=0$ & $=$ \\
\hline 2018 & 1500 & תנם & סמד t & (1) & D & 100 & $0 \$ 00$ & 0.00 & 0.540 & 0 & נוגנ0 & 212 & 100 \\
\hline 2013 & 1500 & 0.000 & ס28 1 & 040 & +100 & 120 & onis & $a \infty$ & 0.700 & متش 0. & oxm & $0.1 \mathrm{a}$ & 100 \\
\hline 2010 & 2000 & 0.04 & 170 & 150 & 110 & $1 \infty 01$ & סמת 1 & 0,10 & 0.170 & 100 & 0 & 010 & 1800 \\
\hline 2016 & 2000 & S & $1 \times 0$ & 0 & 1213 & 10 & 100 & 1000 & 0.100 & 2000 & o:11 & 0.10 & 2000 \\
\hline
\end{tabular}

\section{- SPECIFICATIONS}

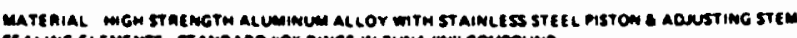

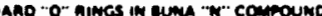

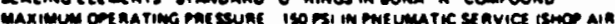

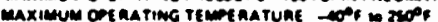

ExTeanal anigh sthia tix

imiganal buanicant to mos tuat

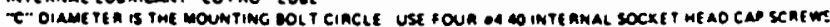

- PINCH FORCE. GRIPPER WT. \& FINGER ROTATION

\begin{tabular}{|c|c|c|c|}
\hline Ganimen n wUWoe $n$ & 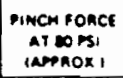 & 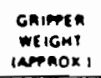 & 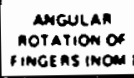 \\
\hline $2812 \times 16 . \times 20$ & $\bullet$ & 20 & 20 \\
\hline$x 11 \times 17+x 21$ & so. & $4 a$ & $x^{\circ}$ \\
\hline$x+4 \times 10,2022$ & 160 & 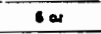 & 1,0 \\
\hline$x=13 \times 10.2023$ & 93 & oos & $10^{\circ}$ \\
\hline
\end{tabular}

Three-fingered gripper--Models 2615 and 2623 


\section{- machinimg stakdaRd for fingers}

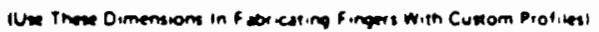

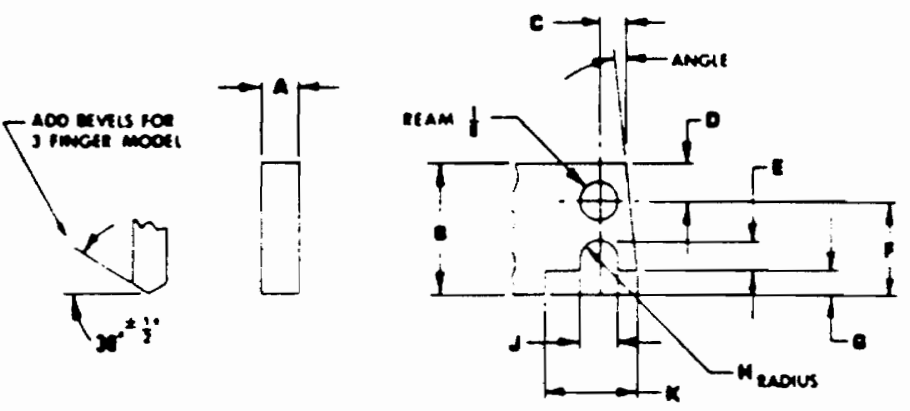

\begin{tabular}{|c|c|c|c|c|c|c|c|c|c|c|c|}
\hline $\begin{array}{l}\text { GRIPPEA } \\
\text { PART NUMBER }\end{array}$ & \pm 002 & Nom & $=\frac{\infty}{c}$ & $\begin{array}{c}-\infty \\
0\end{array}$ & $\begin{array}{c}+\cos \\
E\end{array}$ & $=0$ & $\begin{array}{c}+\cos \\
6\end{array}$ & NOM & $\begin{array}{c}: \infty 2 \\
J\end{array}$ & $: \infty$ & - $x^{0}$ \\
\hline $2600 \times 0012600$ & 121 & 0438 & 125 & 185 & 100 & 313 & $\infty 82$ & $\infty$ & 127 & 313 & $\infty$ \\
\hline 2001.2005 .2600 & .121 & 0.400 & 125 & 125 & 100 & 344 & 120 & $\infty 3$ & 121 & 313 & $\infty$ \\
\hline 2002.2006 .2610 & .184 & 0110 & 156 & 156 & 150 & 563 & 205 & 063 & 127 & 375 & $\infty$ \\
\hline 2000.2001 .2611 & .184 & 1000 & 190 & 156 & 100 & 813 & 219 & oss & 190 & 500 & $7^{\circ}$ \\
\hline
\end{tabular}

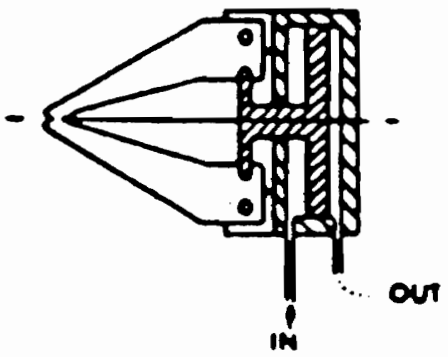

Three-fingered gripper finger design 


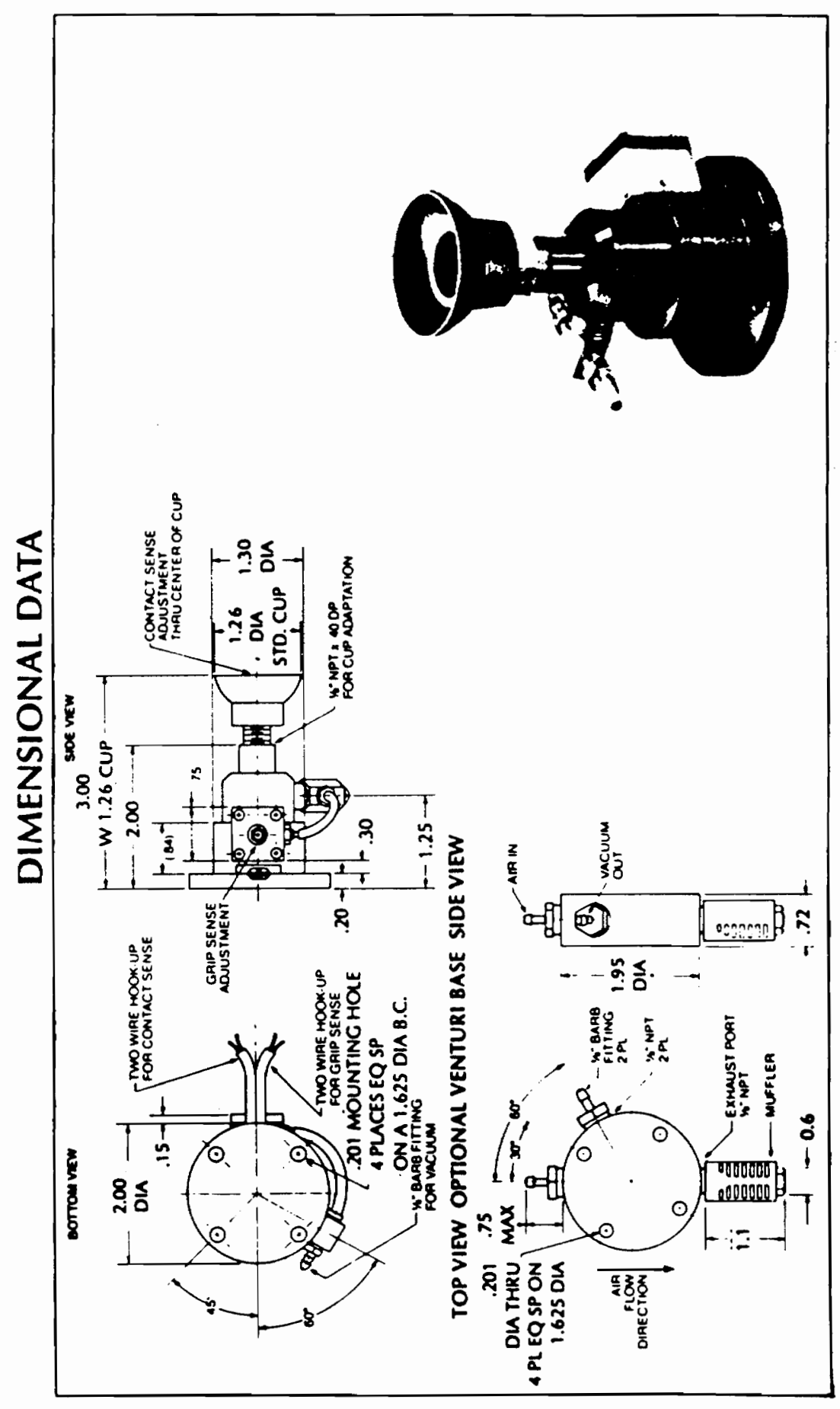



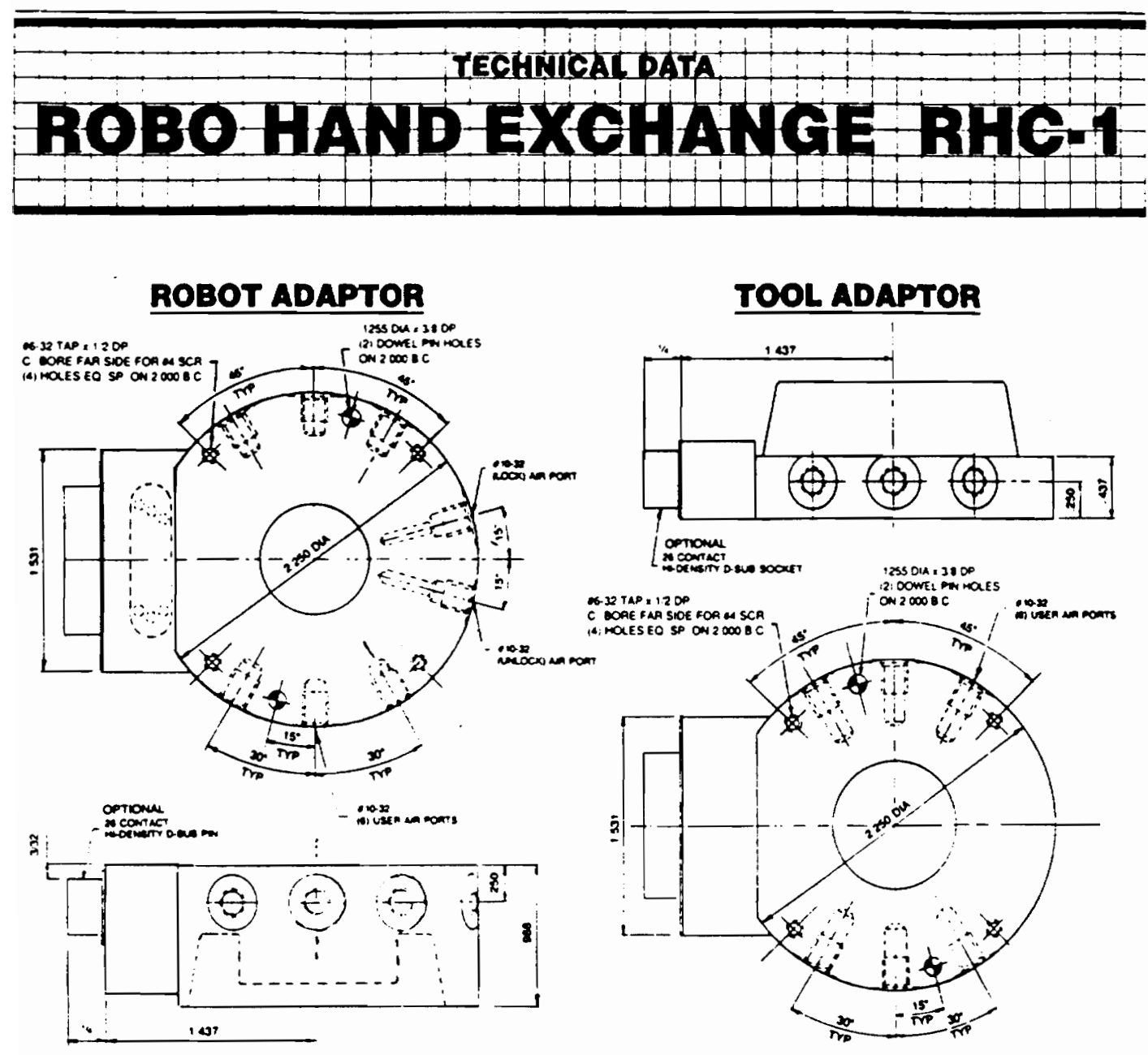

\section{RHC-1 COUPLED}

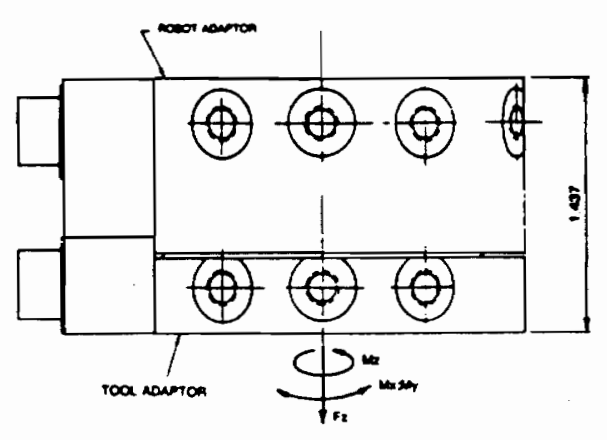

\begin{tabular}{|c|c|}
\hline \multicolumn{2}{|c|}{ SPECIFICATIONS RHC-1 } \\
\hline Size & $21 / 4 \mathrm{Dia}$ \\
\hline Weight & 1002. \\
\hline \multicolumn{2}{|l|}{ MAXIMUM PAYLOAD: } \\
\hline$-F_{2}$ (lbs.) & 200 \\
\hline$-M_{2}$ (in lbs.) & 250 \\
\hline -Mx. My (in Ibs.) & 125 \\
\hline \multicolumn{2}{|c|}{ LOCATION REPEATABILITY WITHIN: } \\
\hline$-X, Y, Z$ axes & .001 \\
\hline \multicolumn{2}{|l|}{ ROBOT TO TOOL INTERFACE } \\
\hline - Electrical Contacis & $26 @ 3 A$ \\
\hline - Pneumatic & $6 \oplus 110-32$ \\
\hline
\end{tabular}




\section{BIBLIOGRAPHY}

[1] Alvite, Joseph. Industrial End Effectors, Proceeding - Robots 8 Conference,

Volume Two: Future Considerations, Society of Manufacturing Engineers, Dearborn, Michigan, 1984, pp. 17-38 to $17-46$.

[2] Anand, D. K. Introduction to Control Systems, Pergamon Press, Ltd., Elmsford, New York, 1984.

[3] Babcock, S. M. and J. Barhen. Real-Time Algorithms for Robotic Control of Teleoperators, Proceeding - Robots 8 Conference, Volume Two: Future

Considerations, Society of Manufacturing Engineers, Dearborn, Michigan, 1984, pp. 19-72 to $19-87$.

[4] Crawford, Keith R., Rick Edwards, Andrew V. Fisher, and Peter E. McCormick. Intelligent Interchangeable Robotic End-of-Arm Tooling, Proceedings - Robots 8 Conference, Volume Two: Future Considerations, Society of Manufacturing Engineers, Dearborn, Michigan, 1984, pp. 17-31 to 17-37.

[5] Federal Bureau of Investigations. 1991 Bomb Summary, FBI Bomb Data Center, Quantico, Virginia, 1992. 
[6] Fisher, John J. Applying Robots In Nuclear Applications, Proceedings - Robots 9 Conference, Volume One: Advancing Applications, Robotics International of the Society of Manufacturing Engineers, Dearborn, Michigan, 1985, pp. 8-1 to 8-19.

[7] Herman, Steven J. Army EOD Robotic Master Plan, Information paper dated 5 November 1991 from office ATSK-CME.

[8] Herman, Steven J. Explosive Ordnance Disposal (EOD) Joint Service Materiel Acquisition Process, Information paper dated 11 September 1992 from office ATGH-CME.

[9] Herman, Steven J. Remote Controlled Reconnaissance Monitor (RECORM), Information paper dated 10 September 1992 from office ATGH-CME.

[10] Herman, Steven J. Army Explosive Ordnance Disposal (EOD) Robotic Master Plan, Information paper dated 11 September 1992 from office ATGH-CME.

[11] Herman, Steven J. Remote Ordnance Neutralization System (RONS), Information paper dated 10 September 1992 from office ATGH- CME.

[12] Hessler, Walt. Application of Commercially Available End of Arm Tooling, Proceedings - Robots 10 Conference, Robotics International of the Society of Manufacturing Engineers, Dearborn, Michigan, 1986, pp. 8-48 to 8-56.

[13] Koren, Yoram. Robotics For Engineers, McGraw-Hill, Inc., 1985. 
[14] Mack Corporation. Handbook - Two, Three and Four Finger Pneumatic Grippers, Mack Corporation, Flagstaff, Arizona, 1990.

[15] Malone, Thomas B., Mark Kirkpatrick III, and Thomas L. Seamster. Operator Interface in the Control of Telerobotic Systems, Proceedings - Robots 12 and Vision 88' Conference, Volume One, Society of Manufacturing Engineers, Dearborn, Michigan, 1988, pp. 3-83 to 3-97.

[16] Martin, H. L. and W. R. Hamel. Joining Teleoperation With Robotics for Remote Manipulation in Hostile Environments, Proceeding - Robots 8 Conference, Volume One: Applications For Today, Society of Manufacturing Engineers, Dearborn, Michigan, 1984, pp. 9-1 to 9-17.

[17] Mertens, Peter. An Industrial Palletizing System For Industrial Robots, Virginia Polytechnic Institute and State University, Blacksburg, Virginia, November 1985.

[18] Mutter, Randolph F. Joining Your End Effector To Your Robot, Proceedings Robot 9 Conference, Volume One: Advancing Applications, Robotics International of the Society of Manufacturing Engineers, Dearborn, Michigan, 1985, pp. 11-104 to 11-107.

[19] Nof, Shimon Y. Handbook of Industrial Robotics, John Wiley \& Sons, Inc., 1985. 
[20] Rosenbrock, Howard. Machines With A Purpose, Oxford University Press, New York, 1990.

[21] SMC 101-588, EOD Mobile Robot System, Standard Manufacturing Company, Inc., Dallas, Texas, 15 October 1988.

[22] Vranish, John M. Quick Change System For Robots, Proceedings - Robots 8 Conference, Volume Two: Future Considerations, Society of Manufacturing Engineers, Dearborn, Michigan, 1984, pp. 17-74 to 17-97.

[23] Wright, Allen J. End Effector Technology and Programmed Automatic Exchange, 13th International Symposium on Industrial Robots and Robots 7 - Conference Proceedings, Volume Two: Future Directions, Society of Manufacturing Engineers, Dearborn, Michigan, 1983, pp. 18-1 to 18-13. 


\section{VITA}

Deborah Mae Chubb was born December 5, 1962 in Waverly, New York. She is the daughter of M. Wendell and Elinor Chubb, who currently reside in Troy, Pennsylvania. Deborah graduated with honors from Troy High School in Troy, Pennsylvania in 1980. She received a Bachelor of Arts in Marine Science from Kutztown University of Pennsylvania in May 1984. Upon graduation from college she entered the United States Army and currently holds the rank of captain. Deborah graduated with a Master of Science degree in Industrial and Systems Engineering from Virginia Polytechnic Institute and State University (Virginia Tech) in May 1993.

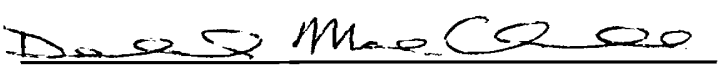

Deborah Mae Chubb 